\title{
The cardiovascular effects of obstructive sleep apnoeas: analysis of pathogenic mechanisms
}

\author{
M.R. Bonsignore, O. Marrone, G. Insalaco, G. Bonsignore
}

The cardiovascular effects of obstructive sleep apnoeas: analysis of pathogenic mechanisms. M.R. Bonsignore, O. Marrone, G. Insalaco, G. Bonsignore. CERS Journals Ltd 1994.

ABSTRACT: Obstructive sleep apnoeas (OSA) exert immediate marked cardiovascular effects, and may favour the development of systemic and pulmonary hypertension in the long-term.

As for the pathogenesis of the acute cardiovascular changes, the first studies highlighted the role of OSA-induced hypoxia and mechanical changes. However, more recent work pointed to the role played by the arousal reaction terminating OSA, and to the activity of the autonomic nervous system during apnoea and inter-apnoeic phase.

As for the pathogenesis of chronic cardiovascular changes, recent findings suggest that the link between OSA and systemic hypertension may be through an abnormal function of the carotid body and underline the importance of chronic intermittent hypoxia versus continuous hypoxia in the development of stable systemic hypertension. On the other hand, OSA do not appear to enhance strongly the development of stable pulmonary hypertension.

In this review, we analyze OSA-induced cardiovascular changes with particular emphasis on to the interplay of the possible pathogenic mechanisms involved. Acute OSA-induced cardiovascular alterations during the apnoeic phase appear to result mainly from the mechanical effects of OSA, while during the interapnoeic phase they seem mostly determined by chemical factors (hypoxia, hypercapnia) and by the arousal reaction. In addition, the role of reflex changes elicited by resumption of ventilation should be reconsidered, since lung inflation seems to exert a positive effect on the cardiovascular changes occurring at the end of OSA. This would be in contrast with the inhibitory effects described as "lung inflation reflex", and deserves further study. Eur Respir J., 1994, 7, 786-805.
Istituto di Fisiopatologia Respiratoria CNR, Palermo, Italy.

Correspondence: M.R. Bonsignore Istituto di Fisiopatologia Respiratoria CNR Via Trabucco 180 90146 Palermo Italy

Keywords: Autonomic nervous system heart rate

pulmonary hypertension

sleep phases

systemic hypertension

Received: July 161993

Accepted for publication September 31993

Supported by Italian National Research Council (CNR). Targeted Project "Prevention and Control of Disease Factors"; Subproject "Control of Cardiovascular Disease".
Both the acute and long-term cardiovascular effects of obstructive sleep apnoeas (OSA) result from a multifactorial pathogenesis, and their study is complicated by the possibly contrasting effects of the different pathogenic factors involved. With respect to acute changes, OSA may elicit reflexes similar to those occurring during voluntary apnoea or diving [1], but such effects are modified by the mechanical effects of the intrathoracic pressure changes secondary to airway obstruction [2]. The responses to peripheral and central chemoreceptor activation by hypoxia and hypercapnia [3] are affected by the sleep state $[4,5]$, as well as the circulatory control $[6,7]$. Parasympathetic tone is high during sleep [8], but the sympathetic system is activated during apnoeas [9] and is likely to be involved in OSA-induced cardiocirculatory changes. Finally, most OSA end with an arousal, which increases sympathetic activity, blood pressure, and heart rate $[10,11]$. Therefore, OSA-induced acute circulatory changes should be considered as integrated responses to different pathogenic factors acting simultaneously or in rapid succession.

Concerning long-term changes, they are also the result of a multifactorial pathogenesis. Both pulmonary and systemic arterial hypertension in OSA patients may depend, directly or indirectly, on the effects of apnoeas, as well as on other factors, like obesity. In addition, the longterm cardiovascular effects of OSA are clinically relevant. Epidemiological studies have shown that OSA and systemic hypertension are often associated [12-21]. Even uncomplicated snoring may increase the risk for cardiovascular diseases [20,22-26], possibly by potentiating the effect of other risk factors [27]. Since the prevalence of undiagnosed sleep-related disordered breathing may be higher than previously believed, especially in women [28], the acute and long-term cardiovascular effects of OSA are potentially major health problems, in addition to raising an interesting physiological puzzle.

OSA-related cardiovascular changes have been the subject of many reviews [15, 17, 19, 20, 29-35]. Attention to sleep medicine is increasing [36], and new data on the circadian behaviour of cardiovascular, hormonal, and nervous variables have recently been published. This widespread growth of interest has taken advantage of modern technology, since miniaturization of recorders 
and development of software for computer analysis has allowed cardiovascular monitoring in ambulatory patients, without major alterations of their sleep pattern [37]. In addition, experimental models of OSA in animals have been established [38-41], and may help in the study of individual pathogenic factors, despite some limitations such as species differences, or experimental designs which do not entirely mimic human OSA.

This review is centred on the factors believed to play a role in the pathogenesis of OSA-induced acute and long-term circulatory changes. After discussing some aspects of cardiovascular regulation during sleep, we describe the time course of heart rate (HR), cardiac output $(\mathrm{CO})$, pulmonary arterial pressure (PAP), and systemic arterial blood pressure (BP) during OSA, with special attention to the role of: 1) hypoxaemia and hypercapnia; 2) the mechanical effects of OSA; and 3) the arousals at the end of the apnoeic events. The importance of the sympathetic nervous system is highlighted, since it is normally involved in cardiovascular regulation during sleep [42], and may mediate the effects of OSA-induced hypoxia and arousals. Finally, the role of OSA in the pathogenesis of diurnal pulmonary and systemic hypertension is discussed.

\section{The cardiovascular system in normal sleep}

The cardiovascular changes normally occurring during human sleep were first related to the sleep phases in the 1960s [43, 44]. It was shown that during non-rapid eye movement (NREM) sleep, HR and CO decreased by $5-10 \%$ compared to wakefulness, and that the $\mathrm{CO}$ reduction might depend mainly on decreased HR, since stroke volume (SV) remained unchanged [44]. While PAP did not change significantly [45], BP decreased during sleep $[46,47]$, due partly to recumbency, and partly to sleep itself [48]. Muscle sympathetic nervous activity (SNA) also decreased progressively during NREM sleep [42, 49]. During rapid eye movement (REM) sleep, a highly variable haemodynamic pattern was reported [43, 44], together with evidence of peripheral vasoconstriction and increased sympathetic vasomotor activity [42, 44].

The sympathetic nervous system is believed to make an important contribution to cardiovascular homeostasis during the REM phase [50]. Recent studies in humans have shown that muscle SNA increased above the wakefulness level during tonic REM sleep [42, 49], and fell whenever muscle tone increased (REM twitches), concomitant with an increase in BP [42]. Increased muscle SNA and BP coincided with the phasic eye movements of REM sleep [10, 51], while muscle SNA tended to decrease as REM sleep duration increased [51]. Auditory stimuli causing arousals during NREM sleep also gave rise to a transient increase in muscle SNA and BP [10, 51]. It should be emphasized that muscle SNA, although physiologically important, is only part of total SNA. While muscle SNA is dominated by vasoconstrictor impulses [52], skin SNA shows different features, such as dependency on thermoregulation, coupling with inspiration, and increase with arousal stimuli [53]. Changes in skin SNA during sleep have received much less attention than changes in muscle SNA. In normal subjects, skin SNA was reported to decrease during NREM sleep [44, 53], whereas variable changes were found during REM sleep [44, 53].

Further studies are needed to give a better understanding of the role of SNA during sleep and OSA, particularly since the sympathetic nervous system may, for the most part, regulate the distribution of peripheral blood flow rather than simply affecting total peripheral resistance during sleep. In cats, a profound vasodilation occurred during REM sleep, together with lack of sympathetic responses and of thermal regulation $[6,7]$; however, this was accompanied by mesenteric vasodilation and iliac vasoconstriction [6]. Therefore, the analysis of cardiovascular regulation during sleep appears complicated, especially in humans where the distribution of blood flow is hard to investigate. Among the few areas studied, subcutaneous adipose tissue was shown to undergo vasodilation at the onset of deep NREM sleep, while its blood flow rate was stable during REM sleep [54]. Cerebral blood flow decreased during NREM and increased during REM sleep, possibly in relation to changes in brain metabolism [55, 56]. Intracranial blood flow velocity, measured by transcranial Doppler and corrected for $\mathrm{PETCO}_{2}$, remained fairly constant during sleep in normal subjects [57].

The sleep state may also modify cardiovascular regulation through other mechanisms, directly or by modulating SNA. For example, experimental data suggest that the parasympathetic and sympathetic systems may variably interact during the different sleep phases [8]. In addition, the baroreceptor-cardiac reflex was shown to undergo resetting during sleep [46], while its sensitivity, inconsistently affected during NREM, increased during REM sleep $[46,58]$. Thermoregulation, was found to be blunted during REM sleep in humans [59]. In summary, this brief description underlines the fact that sleep-related cardiocirculatory changes may result from complex adjustments involving different homeostatic mechanisms. Cardiovascular regulation in normal conditions appears to be affected mainly by the sleep phases, and by the related changes in activity of the autonomic nervous system [60].

\section{Acute cardiovascular changes in obstructive sleep apnoeas}

\section{Heart rate (fig. 1)}

OSA-related HR changes are so characteristic that they may suggest the diagnosis of the OSA syndrome [61]. HR decreases during apnoeas and increases abruptly immediately post-apnoea [62], this pattern occurring cyclically during sleep [61]. ZwILLICH et al. [63] compared HR immediately before and at the end of apnoeas of different duration, and concluded that the development of bradycardia in OSA was directly related to apnoea length and arterial oxygen desaturation. The sleep phase seemed not to affect HR changes, since the profound bradycardia of REM sleep could be accounted for by more 


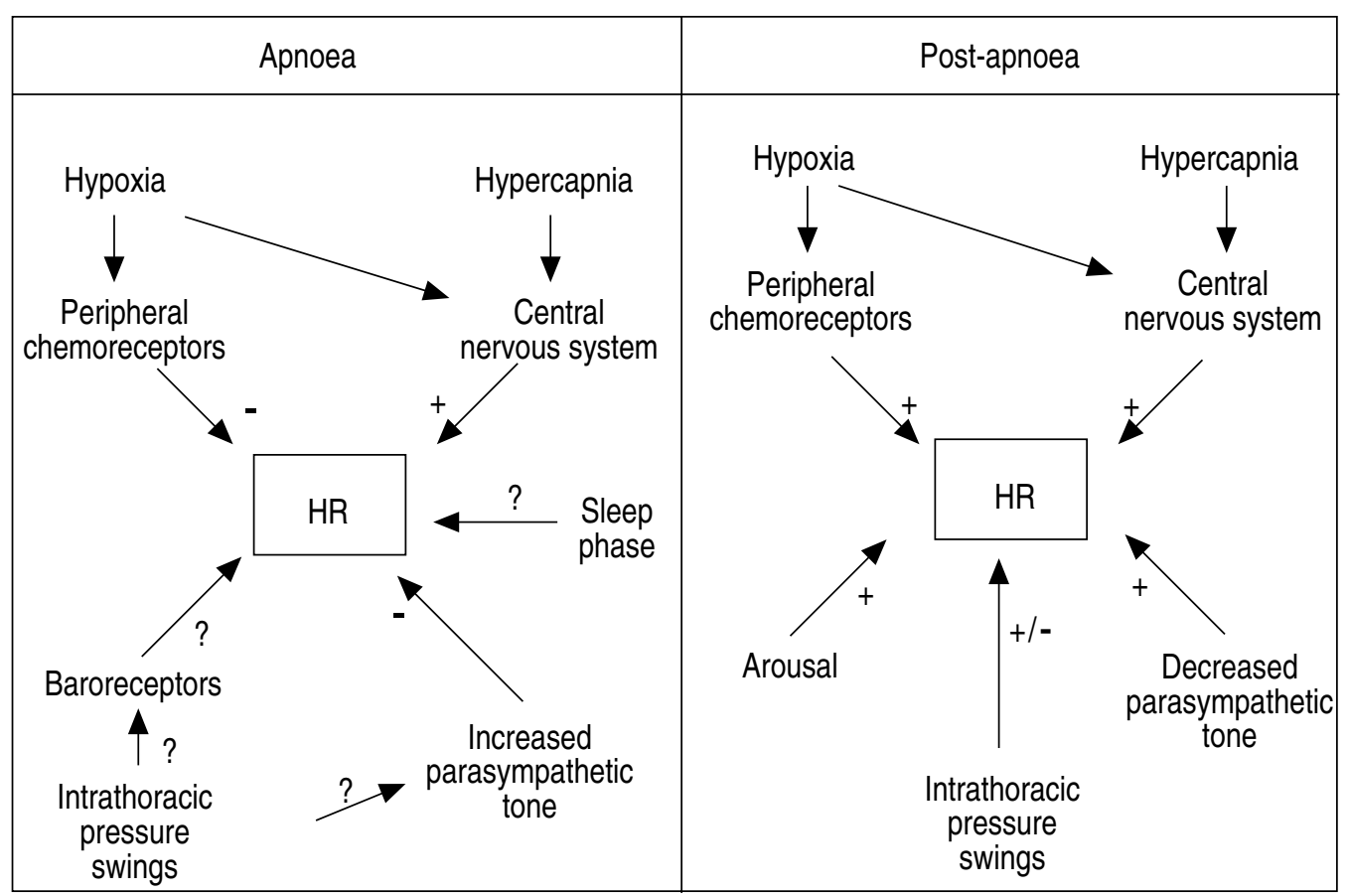

Fig. 1. - Schematic summary of the influence of various pathogenic factors on heart rate (HR) during apnoeas and immediate post-apnoea (details in the text).

prolonged and desaturating apnoeas than during NREM sleep. In awake OSA patients, ventilation with hypoxic mixtures increased HR. This study concluded that both apnoea and hypoxia contributed to the pathogenesis of bradycardia in OSA [63], in agreement with the classic studies on the pulmonary inflation reflex (hypoxia causes either bradycardia or tachycardia according to the absence or presence of ventilation, respectively) [64]. The role of OSA-induced progressive hypercapnia on HR was not examined [63], but experiments in normal subjects during wakefulness indicated that hypercapnia may slightly counteract both apnoea- and hypoxia-induced bradycardia [65]. In summary, in humans, the effect of apnoea on HR may be similar during wakefulness and sleep.

However, other studies have indicated that activation of peripheral chemoreceptors may not be the only factor responsible for the OSA-induced decrease in HR. Bradycardia only partially reverted following oxygen administration during OSA [61, 63]. In awake normal subject, the HR changes of OSA were mimicked by tidal breathing interrupted by recurrent apnoeas, but were unaffected by oxygen administration, suggesting that, during OSA, HR may be modulated mainly by other mechanisms [66]. Peripheral chemoreceptors could play a minor or no role in regulating HR during hypoxia, as indicated by the finding that ventilation with hypoxic mixtures in carotid body-resected awake humans caused tachycardia, as in normal subjects $[67,68]$. In addition to stimulating peripheral chemoreceptors, hypoxia has central nervous system effects, suggesting that HR changes during OSA may be the result of the simultaneous activation of different reflex pathways. Indeed, hypoxia of peripheral chemoreceptors in conditions of constant ventilation caused bradycardia, whereas hypoxia of the cen- tral nervous system increased sympathetic outflow and HR [69]. Moreover, in addition to this difference between central and peripheral responses, the peripheral (carotid and aortic) chemoreceptors could respond differently to hypoxia and hypercapnia [3], further complicating the analysis of the HR behaviour.

Furthermore, since respiratory efforts due to upper airway obstruction develop during OSA, HR may be affected, directly or indirectly, by mechanically-induced changes in other cardiovascular variables (for example, SV or BP) through baroreceptor activation. This hypothesis was tested by studying the HR response to phenylephrine during wakefulness and sleep in normotensive and hypertensive OSA patients [70], but the results did not confirm it. Although the cardiac baroreflex sensitivity differed between the two groups, the absolute and relative HR changes during the apnoeic cycle were similar in normotensive and hypertensive patients [70]. Therefore, the cardiac baroreflex did not explain OSA-induced bradycardia.

Increased parasympathetic tone appears to contribute to the bradycardiac response [71], since atropine prevented the decrease in HR during OSA [61, 63]. In OSA patients, the HR response to the Müller or Valsalva manoeuvre during wakefulness predicted the HR changes observed in OSA, whether or not concomitant hypoxaemia occurred [71]. OSA-induced HR changes may depend on the stimulation of upper airway receptors, possibly increasing parasympathetic efferent activity even in the absence of lung inflation and stretch receptor stimulation [72]. OSA patients responded with bradycardia to the Müller manoeuvre, whereas normal subjects did not, suggesting that upper airway obstruction may activate parasympathetic receptors at the site of airway collapse or distortion [72]. 
Respiratory sinus arrhythmia (higher HR during inspiration than during expiration) [73] can be demonstrated during OSA, suggesting that respiration modulates HR even during obstructed breathing [74]. This modulation could result from a direct central interaction between respiratory and cardiovascular control centres [75], or from activation of peripheral receptors indirectly increasing parasympathetic efferent activity [72].

Compared to the marked sinus arrhythmia found when examining the whole apnoea-interapnoeic phase cycle [61], HR changes during the apnoeic phase appear relatively small. Recently, it was suggested that HR may behave differently during OSA in NREM and REM sleep [76], thus challenging the conclusion reached by ZwILLICH et al. [63]. In NREM sleep, HR was lowest at the beginning and increased towards the end of apnoeas, whereas during REM sleep it progressively decreased during apnoeas. Whilst confirming the relationship between bradycardia and hypoxia, these results suggested an independent effect of the sleep phase on HR during OSA [76]. Other investigators found variable HR changes in OSA [77], or a modest trend to progressive bradycardia during NREM OSA [78].

Although OSA-induced HR changes may be modulated by different factors (apnoea, hypoxia, parasympathetic activity, sleep phase), an intact autonomic nervous system is necessary for HR changes to occur, since a stable HR was found during OSA in patients with autonomic dysfunction $[61,79,80]$. Spectral analysis may be employed to analyse the sympathetic-parasympathetic balance in relation to HR changes during sleep [81-84]. Unfortunately, HR in OSA does not vary in a sinusoidal fashion, which is a prerequisite of any method applying Fourier analysis [85]. The few published data have documented a high HR variability in OSA patients during sleep [86], and a phase difference between HR and BP changes, not supporting a major role for baroreflexes during OSA [87].

Post-apnoeic tachycardia also deserves comment. It may be an effect of hypoxia, increasing HR at the resolution of airway obstruction when the pulmonary inflation reflex is re-established [64]. In addition, the arousal reaction could increase HR by increasing SNA [10]. A decrease in parasympathetic tone may also occur, as suggested by the blunted respiratory sinus arrhythmia found immediately post-apnoea [74]. Therefore, a crucial role for the autonomic nervous system in the post-apnoeic phase seems likely. In OSA patients, post-apnoeic HR tended to be higher in REM than in NREM sleep, and peak HR significantly correlated with the HR response to the Valsalva manoeuvre [76]. In snorers, the smallest post-apnoeic increase in HR was found in the patients with the highest apnoea-hypopnoea index (AHI), suggesting that the HR response to apnoeas may reflect the degree of "brainstem arousability" [88]. The intriguing hypothesis that subcortical arousals may be important in the pathophysiology of OSA-related HR changes needs further evaluation, but is supported by another study in normal subjects, reporting that stimuli insufficient to cause electro-encephalographic (EEG) arousals did increase HR and BP [11].
It would be interesting to transform the increasing knowledge on the autonomic nervous system during sleep into clinically useful information. An alternative approach may include studying the responses of OSA patients to autonomic stress tests (AST), although their standardization is difficult. Abnormal responses to AST were more frequently found in OSA patients than in snorers, especially when nocturnal oxygen desaturations were severe [89]. Because the subjects studied were young and without any known cause of autonomic dysfunction, these results imply that abnormal autonomic responses may be very common in the whole population of OSA patients [89], supporting the hypothesis that OSA may reset the threshold of cardiovascular adaptation through chronic autonomic overstimulation.

Cardiac arrhythmias could contribute to increase cardiovascular risk in OSA patients [34]. Besides the sinus arrhythmia already described [61], both bradyarrhythmias (sinus pauses, A-V block of variable degree) and tachyarrhythmias (premature ventricular contractions, ventricular tachycardia) were reported in OSA patients during sleep, but, in the same patients, electrophysiological studies were normal during the daytime [90]. OSA-related disturbances in cardiac rhythm may depend both on the high nocturnal parasympathetic tone (especially for bradyarrhythmias), and the recurrent falls in arterial oxygen saturation $\left(\mathrm{SaO}_{2}\right)$. An important role for hypoxaemia was suggested by the increased frequency of premature ventricular complexes found in severe OSA with very low nocturnal $\mathrm{SaO}_{2}[34,91,92]$. Conversely, nocturnal oxygen administration in patients with OSA and chronic obstructive pulmonary disease (COPD) improved OSAdependent bradycardia, but had no effect on supraventricular or ventricular arrhythmias [93]. However, these results may not be generally applicable to the whole OSA population. Most investigators agree that arrhythmias in OSA disappeared after tracheostomy [90], or under therapy with nasal continuous positive airway pressure (nCPAP) [34].

\section{Cardiac output (fig. 2)}

Knowledge of the time course of cardiac output (CO) when sleep is disturbed by repeated upper airway obstruction is clinically important, since alterations in cerebral or myocardial blood flow may contribute to increase the risk for cardiovascular disease in snorers compared to the general population [23-25]. The velocity of carotid [94] and intracranial blood flow [57] was found to decrease in OSA, more than could be accounted for by the increased $\mathrm{PETCO}_{2}$ during apnoeas [57]. Preliminary data have suggested that cerebral blood flow velocity increased during OSA, but fell rapidly to the initial value post-apnoea, implying that such chronic strain of the brain vessels might lead to microangiopathic vascular lesions [95]. The pathophysiological consequences of these findings are still undefined, as is the relationship between cerebrovascular disease and OSA.

Similarly, coronary blood flow was never measured during OSA, but myocardial oxygen consumption $\left(\mathrm{MV}_{\mathrm{O}_{2}}\right)$ 


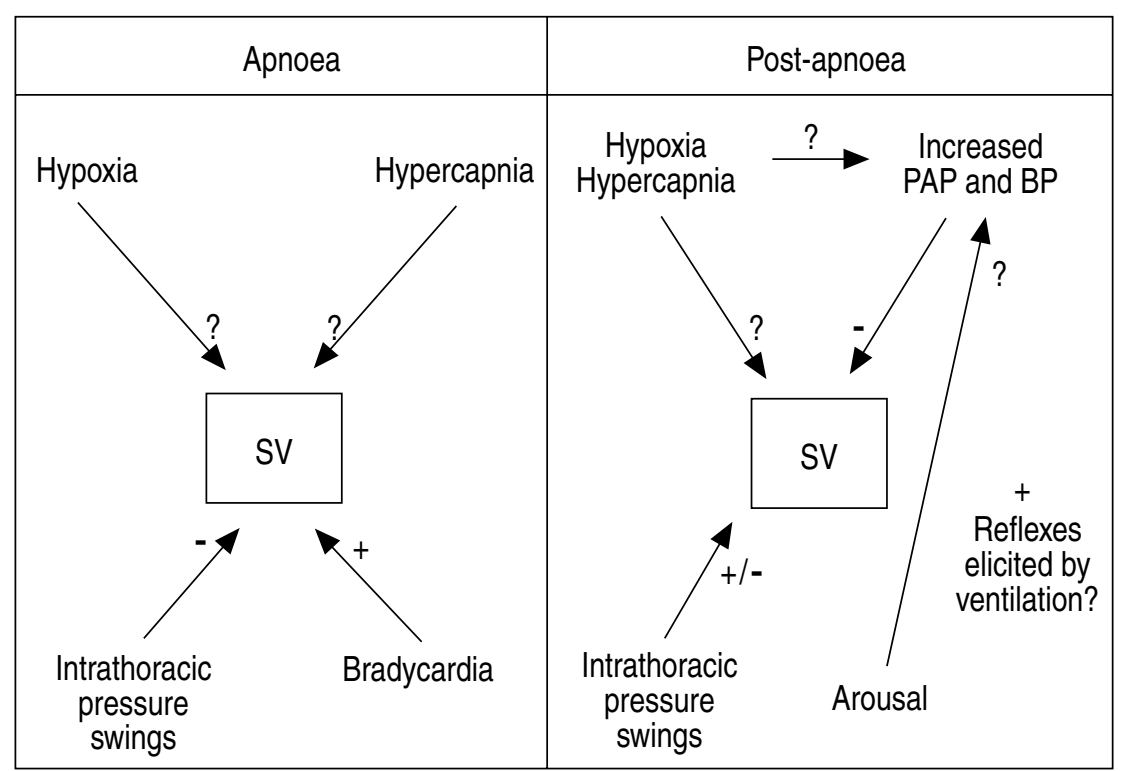

Fig. 2. - Schematic summary of the influence of various pathogenic factors on right and left ventricular stroke volume (SV) during apnoeas and immediately post-apnoea (details in the text). PAP: pulmonary artery pressure; BP: systemic arterial blood pressure.

was estimated, based on the time course of haemodynamic variables during apnoeas [91]. OSA-induced bradycardia may limit $\mathrm{MV}_{\mathrm{O}_{2}}$, but the post-apnoeic increase in $\mathrm{HR}$ and systemic BP are likely to increase $\mathrm{MV}_{\mathrm{O}_{2}}$. Therefore, on theoretical grounds, OSA may significantly reduce myocardial blood flow supply and/or increase demand [91]. Left ventricular (LV) ejection fraction decreased in some OSA patients both during exercise and REM sleep, together with evidence of myocardial hypoperfusion at thallium scintigraphy, suggesting that REM sleep could be as stressful as exercise in OSA [96]. However, no conclusion can be drawn until more data become available on this issue.

Besides these uncertainties concerning the time course of cerebral and myocardial blood flow during apnoeas, measuring total blood flow $(\mathrm{CO})$ in OSA also raises problems. The thermodilution method provides average data over several cardiac cycles and requires measurements in triplicate for validation of results. Since OSA patients show recurrent apnoeas of relatively short duration, it is not surprising that some studies found no significant change in CO during apnoeas or interapnoeic phases [97, 98]. Another study reported that CO decreased during apnoeas, more in REM than in NREM sleep, and increased in the interapnoeic periods [99], but no conclusion could be drawn on such variable results.

Application of beat-by-beat methods during OSA has improved our knowledge of the time course of $\mathrm{CO}$, calculated as stroke volume (SV) times heart rate (HR). Most techniques providing beat-by-beat data are noninvasive, but artifacts caused by lung inflation and/or body movements may prevent data collection during the interapnoeic phase [100, 101]. Thoracic electrical impedance $[76,100]$, echocardiography [101], and, more recently, continuous measurement of left ventricular volume [102] and of blood velocity in the pulmonary artery to estimate right ventricular stroke volume (RVSV) [78] were employed in OSA. CO was found to be well-maintained during NREM OSA (fig. 2), since HR and SV underwent reci- procal changes during the apnoeic phase without significant effects on $\mathrm{CO}[76,78,102]$. CO decreased during apnoeas in REM sleep, since HR progressively fell during apnoea and SV remained at the pre-apnoeic level ([76], Bonsignore, unpublished observations). Interestingly and unexpectedly, $\mathrm{CO}$ was found to decrease post-apnoea (fig. 2), due to a decrease in SV not compensated for by the post-apnoeic increase in HR [78, 102]. This conclusion was reached by two studies using unrelated methodologies to monitor left ventricular stroke volume (LVSV) and RVSV, respectively, and appeared at variance with previous data [99]. The post-apnoeic decrease in LVSV coincided with an abrupt increase in end-systolic LV volume and BP [102]. The post-apnoeic decrease in RVSV was explained as possibly resulting from a limitation of $\mathrm{RV}$ diastolic filling or from increased pulmonary vascular resistance caused by lung expansion [78]. In fact, most of the post-apnoeic decrease in RVSV occurred at maximal inspiration [78] (fig. 3). During post-apnoea, it

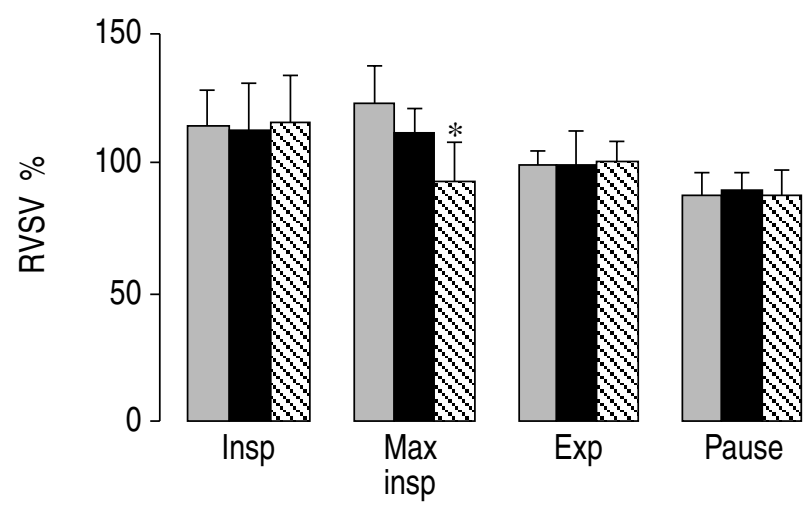

Fig. 3. - Distribution of right ventricular stroke volume (RVSV) (\% of mean value for each apnoeic phase $\pm \mathrm{SD}$ ) in the respiratory cycle before, during and after obstructive apnoeas $\square$ : pre-apnoea; apnoea; $\times$ : post-apnoea. Insp: inspiration; Max insp: maximal inspiration; Exp: expiration; pause: late expiration, when oesophageal pressure is stable. 
is likely that the autonomic nervous system is simultaneously affected by different factors, i.e. hypoxia, arousal, and lung inflation, and changes in SNA may contribute to acutely decrease SV immediately post-apnoea. However, the data available during OSA indicate that muscle SNA, after a progressive increase during apnoeas, fell abruptly at resumption of ventilation [9], probably because of both increased oxygen tension [9] and the pulmonary inflation reflex [64]. The post-apnoeic decrease in SV seemed to occur at the same time that muscle SNA decreased, but the relationship between changes in SNA and SV during OSA has not been investigated. Interestingly, preliminary data suggest that skin SNA, evaluated from changes in finger plethysmographic volume, increased at the resumption of ventilation after OSA [53], raising the question of the relative pathophysiological significance of muscle and skin SNA changes during apnoeas. Insufficient data are available at present to provide any answer.

The arousal reaction seems to play a minor role in the post-apnoeic decrease in CO, for LVSV did not change after isolated arousals, whereas delaying the resumption of ventilation delayed the post-apnoeic LVSV fall [103]. The post-apnoeic decrease in RVSV and LVSV was documented only during NREM OSA [78, 102], but preliminary data indicate that it may also occur in REM OSA, as well as at the resolution of partial airway obstruction during snoring (fig. 4) (Bonsignore, unpublished observations). Whatever the mechanism(s) responsible, the SV changes immediately post-apnoea suggest an effect of reflex adjustments originating from lung inflation [104].
This issue deserves further study, to define the pathophysiological aspects, as well as its clinical relevance in OSA patients and snorers.

Beat-by-beat analysis of SV has provided information about the mechanical effects of OSA on the circulation. Intrathoracic pressure influences SV by affecting cardiac filling pressure (preload), and transmural PAP and BP (afterload) [2]. Moreover, mechanical changes affect the heart indirectly through the ventricular interdependence mechanism: since the septum is common to both ventricles, it can be shifted by increased filling of one ventricle, thus decreasing the filling of the other [105]. During normal breathing, inspiration increases RVSV and decreases LVSV slightly, the opposite occurring in expiration. These small, respiratory-dependent variations become marked oscillations during airway obstruction [2]. Echocardiographic monitoring has documented decreased LV diastolic dimensions and left ventricular collapse during OSA [101]. Beatby-beat analysis of LVSV relative to intrathoracic pressure during OSA has revealed that LVSV was stable at oesophageal pressures (Poes) $\geq-10 \mathrm{cmH}_{2} \mathrm{O}$, but decreased linearly at Poes <-10 $\mathrm{cmH}_{2} \mathrm{O}[100]$. Subsequent studies reported that LVSV changes during OSA could be accounted for not only by changes in Poes, but also by HR changes during apnoea, SV at onset of apnoea, and age [76]. SV changes did not correlate with $\mathrm{SaO}_{2}$ changes, suggesting that SV during OSA may be affected more by mechanical events than by hypoxaemia [76].

Mechanically-induced RV changes are opposite to LV changes [2], and RV enlargement was found during OSA

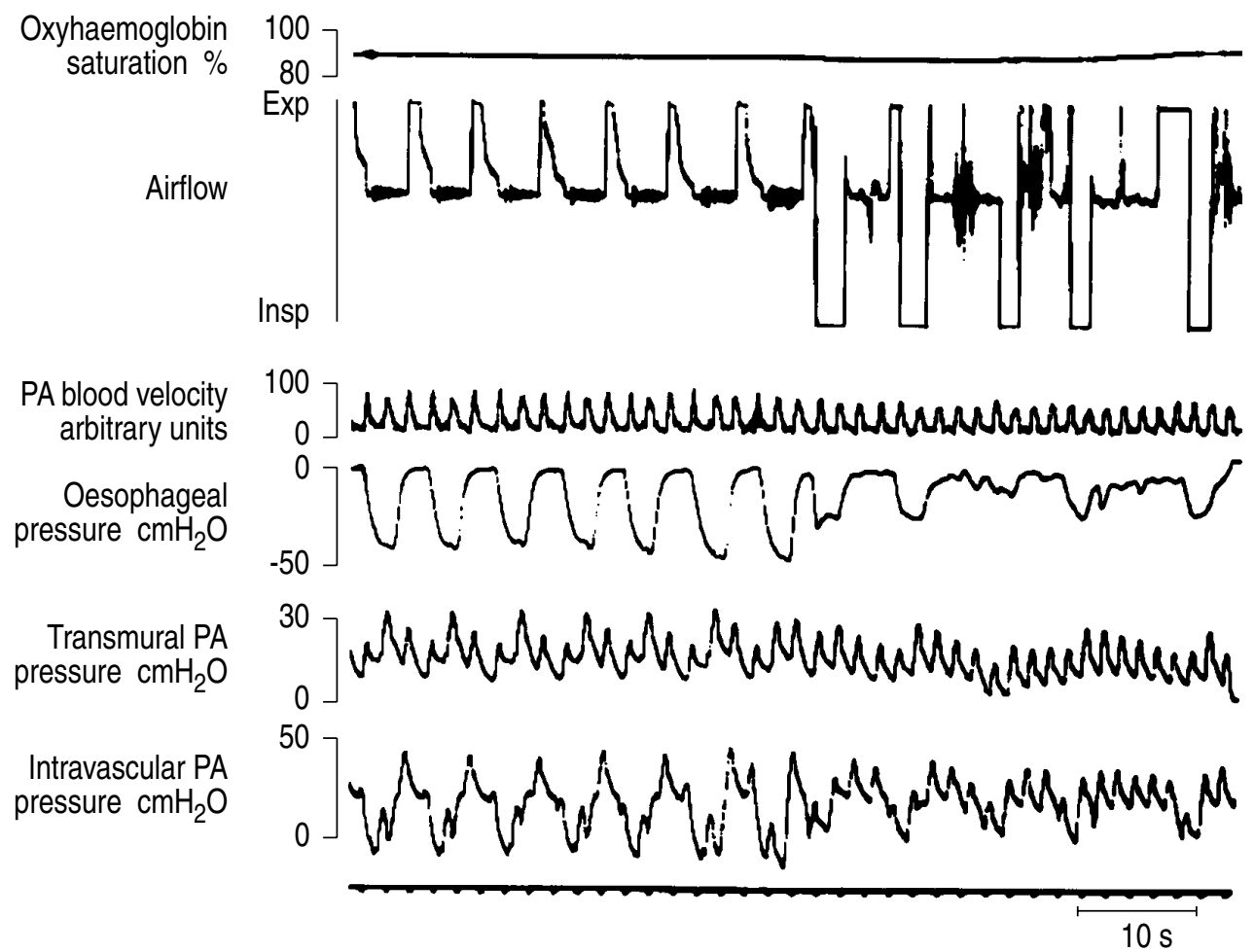

Fig. 4. - Resolution of partial airway obstruction during snoring followed by a decrease in right ventricular stroke volume, as estimated by integration over time of the pulmonary arterial (PA) blood velocity signal. Snoring (left half of figure) is characterized by partial airway obstruction, indicated by marked oesophageal pressure (Poes) swings with inspiratory limitation of airflow. At resolution of snoring, Poes swings decrease and inspiratory flows increase. Meanwhile, the amplitude of the pulmonary arterial (PA) blood velocity signal decreased, suggesting reduction of right ventricular stroke volume, similar to what can be observed at the resolution of obstructive sleep apnoea.. Exp: expiration; Insp: inspiration. 
[101]. Because venous return at low intrathoracic pressures may be limited by collapse of the great veins at the entrance of the chest [106-109], the relationship between RVSV and Poes was studied in a small sample of OSA patients [110]. Preliminary data suggested that RVSV may decrease at low Poes, supporting the hypothesis of a limited venous return at low intrathoracic pressure [107]. However, an effect of increased RV afterload in limiting RVSV at low intrathoracic pressure could not be excluded [110].

It is uncertain whether myocardial contractility is acutely affected by apnoeas [29, 35], but OSA-related SV changes can, for the most part, be explained by mechanical effects [76, 111]. In isolated cardiac fibres, both hypoxia and hypercapnia decreased maximum force and velocity of shortening [112], but regulation of myocardial contractility in the intact animal is more complex [113]. On one side, myocardial contractile strength decreased during hypoxia, possibly due to a carotid chemoreceptorinduced negative inotropic effect [114]. On the other hand, hypoxia of the central nervous system increased cardiac contractility by eliciting a strong sympathetic discharge, and this central response would override the inhibitory effect of carotid body stimulation [69]. The predominance of central over peripheral effects was also suggested by the unchanged cardiac and coronary haemodynamics found during hypoxia in sinoaortic-denervated dogs [115].

If an acute decrease in cardiac contractility during OSA is uncertain, chronic right and/or left ventricular dysfunction can occur in OSA patients [35], and improve under nCPAP treatment $[116,117]$. Therefore, chronic recurrence of OSA, through many possible pathophysiological mechanisms, may adversely affect cardiac function [35]. However, no evidence for LV dysfunction was found in OSA patients, even when selecting a group with severe disease ( $\mathrm{AHI}>40 \cdot \mathrm{h}^{-1}$ with marked nocturnal falls in $\mathrm{SaO}_{2}$ ) [118]. Therefore, the direct role of OSA in the pathogenesis of acute or chronic cardiac dysfunction remains controversial.

\section{Pulmonary arterial pressure (fig. 5)}

The first studies on the pulmonary circulation in OSA described the large oscillations in PAP caused by the intrathoracic pressure swings, and reported that mean PAP increased immediately post-apnoea $[62,119]$. Other investigations reported only maximal PAP values attained during sleep, and suggested that OSA may cause nocturnal pulmonary hypertension [97]. PAP behaviour during OSA was better evaluated by calculating transmural PAP (PAPtm), i.e intravascular PAP minus intrathoracic pressure, that is the true distending PAP [120]. During NREM sleep, systolic and diastolic PAPtm decreased slightly at the beginning of OSA, then increased at the end of the apnoeic phase, and were high at the resumption of ventilation [120]. Increased PAP during OSA could result either from mechanical events [98], or from hypoxic vasoconstriction. A significant inverse correlation between PAPtm and $\mathrm{SaO}_{2}$ was found in most OSA patients, suggesting that hypoxia plays a part in the pathogenesis of nocturnal pulmonary hypertension [120]. This hypothesis was further tested by evaluating the effect of oxygen administration on PAPtm during OSA [121]. If hypoxia contributed to OSA-induced pulmonary hypertension, PAPtm would be lower when nocturnal $\mathrm{SaO}_{2}$ was maintained at values $\geq 90 \%$. However, in most patients, oxygen administration affected neither mean PAPtm, nor the amplitude of PAPtm swings [121]. As possible explanations, prolongation of OSA by supplemental oxygen might increase $\mathrm{CO}_{2}$ retention compared to OSA while breathing room air. $\mathrm{CO}_{2}$ may counteract the effects of oxygen, by constricting pulmonary vessels [122]. Alternatively, PAPtm remained high because the oscillations of PAPtm were dependent on the intrathoracic pressure swings and unaffected by oxygen. PAPtm during oxygen administration decreased in only two patients, both showing a minor increase in transcutaneous carbon dioxide tension $\left(\mathrm{PCO}_{2}\right)$ and being the youngest among the patients studied. This suggests that structural pulmonary

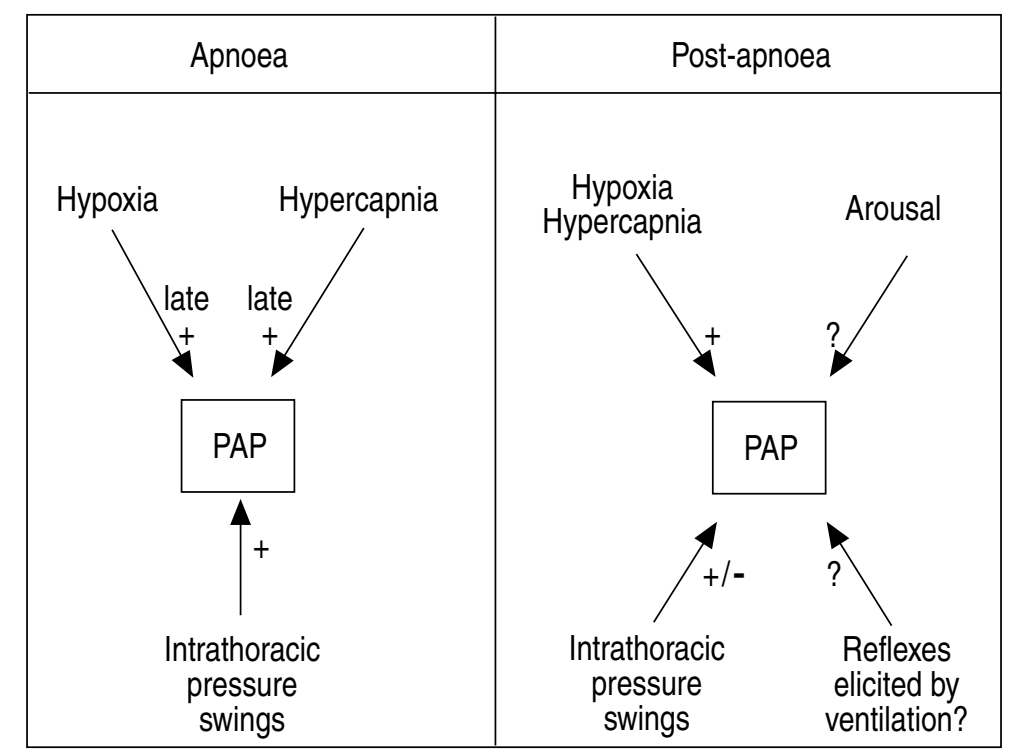

Fig. 5. - Schematic summary of the influence of various pathogenic factors on pulmonary arterial pressure (PAP) during apnoeas and immediately post-apnoea (details in the text). 
vascular changes may influence the pulmonary haemodynamic response to OSA [121]. An additional possibility was that pulmonary hypoxic vasoconstriction may develop slowly, requiring repetitive and profound desaturations to significantly increase PAPtm [121].

OSA during NREM sleep recurs with relatively constant characteristics in each patient, making the analysis of a slow effect of hypoxia difficult. In a dog model of OSA by repetitive airway obstructions of different duration, cardiovascular changes were analysed over a wide range of $\mathrm{SaO}_{2}$ values [39]. At the release of airway occlusion, PAP progressively increased as $\mathrm{SaO}_{2}$ decreased, but oxygen administration prevented the occurrence of the pulmonary hypertensive peaks [39]. Therefore, this study concluded that hypoxia was the major cause of OSArelated nocturnal increases in PAP. In OSA patients, similar results were obtained by comparing PAPtm during NREM and REM sleep in the same subjects [123]. At similar Poes values, PAPtm was higher during REM than NREM OSA, and the difference could be related to the more profound falls in $\mathrm{SaO}_{2}$ observed during REM sleep [123]. Therefore, the role of hypoxia in the pathogenesis of nocturnal pulmonary hypertension in OSA patients is well-documented on both experimental and clinical grounds.

Nevertheless, OSA-induced mechanical changes may also affect the pulmonary circulation [98]. The analysis of PAPtm and pulmonary flow (RVSV) during NREM OSA suggested that pulmonary vascular resistance (PVR) increased at low intrathoracic pressures, because PAPtm increased as Poes decreased, but RVSV might decrease at low intrathoracic pressure (see previous section) [110]. This increase in PVR could not be ascribed to lung volume changes, absent during apnoeas, but may reflect the effects of low intrathoracic pressure on the left heart. Limitation of LV filling and emptying at low intrathoracic pressures $[2,101]$ could at least contribute to increase PVR during OSA by increasing pulmonary venous pressure and blood volume, as suggested in a recent review [35]. This hypothesis is further supported by the high pulmonary arterial wedge pressure documented during OSA [124], and by the possible, albeit infrequent, clinical presentation of OSA as nocturnal pulmonary oedema [125]. Thus, mechanical changes affect PVR during the apnoeic phase, while the pulmonary hypertensive peaks seem to be related mostly to hypoxaemia, since they occur when intrathoracic pressure returns towards normal values and are blunted by oxygen administration [39].

However, hypoxia may not be the only pathogenic factor responsible for the post-apnoeic increase in PAPtm. At the resolution of OSA, the similar behaviour of the pulmonary and systemic circulations (decrease in RVSV [78] and LVSV [102], and increase in pulmonary and systemic vascular resistance) may lead to the hypothesise that a generalized cardiovascular reflex may also play some role. The data available would not confirm the hypothesis of major, reflex-induced pulmonary circulatory changes, since PAP increased similarly during OSA in patients with or without the Shy-Drager syndrome [126]. However, studying reflex mechanisms is difficult, especially for the pulmonary circulation which can only be approached invasively. Preliminary results obtained during repetitive airway obstruction in dogs suggested that an $\alpha$-adrenergic pathway through the carotid body played only a minor role in the pathogenesis of pulmonary hypertension [127]. On the other hand, in anaesthetized dogs, stimulation of peripheral chemoreceptors may inhibit hypoxic pulmonary vasoconstriction, whereas sympathetic activation would reduce pulmonary vascular tone during both hypoxia and hyperoxia [128]. At present, the available data do not allow the role of the autonomic nervous system in modulating the responses of the pulmonary circulation during OSA to be defined. Hopefully, future studies will investigate this issue.

\section{Systemic arterial pressure (fig. 6)}

The time course of changes in systemic arterial blood pressure (BP) during OSA is similar to that of PAP: BP is lowest at the beginning of OSA and increases towards the end of the apnoeic phase, the highest values being recorded during post-apnoea [62]. OSA patients show a high BP variability during sleep [86, 87], and the normal nocturnal decrease in BP can be prevented by the continuous recurrence of OSA [129]. As a result, mean $24 \mathrm{~h} \mathrm{BP}$ is often increased in OSA patients, even when they are normotensive during wakefulness, and this may entail a higher cardiovascular risk [130, 131]. However, development of systemic hypotension during OSA has also been reported, especially in older patients $[77$, 132-134], and is currently ascribed to reduced sympathetic responsiveness to hypoxia in the elderly [135]. Systemic hypotension during OSA may favour occurrence of a stroke by decreasing cerebrovascular perfusion pressure [132], extending the hypothesis that nocturnal cerebrovascular accidents in OSA patients may be caused by the hypocapnia and cerebral vasoconstriction occurring during the hyperventilation periods [136].

Despite the variable time course of BP during apnoeas, the mechanical effect of airway obstruction is recognizable as pulsus paradoxus, coincident with Poes nadirs [101] or mouth pressure changes [137]. Pulsus paradox, i.e. a marked inspiratory decrease in $\mathrm{BP}$, reflects the decrease in LVSV at low intrathoracic pressure [2]. Experimental data suggest that carotid and aortic baroreceptors are differently activated during obstructed breathing or the Müller manoeuvre [138]. During inspiratory efforts, carotid (extrathoracic) baroreceptors were exposed to a lower transmural pressure than aortic (intrathoracic) baroreceptors, and afferent activity from the carotid baroreceptors correspondingly decreased, while that of aortic baroreceptors was unchanged [138]. Therefore, it is possible that mechanically-induced BP oscillations during OSA may be, at least partly, buffered by the differential activation of the baroreceptors.

True hypertensive peaks occur in OSA at resumption of the ventilation, while the intrathoracic pressure swings decrease in amplitude. Since LVSV decreased during post-apnoea despite normalization of intrathoracic pressure [102], the post-apnoeic increase in BP cannot be ascribed to an increase in $\mathrm{CO}$, as previously believed 


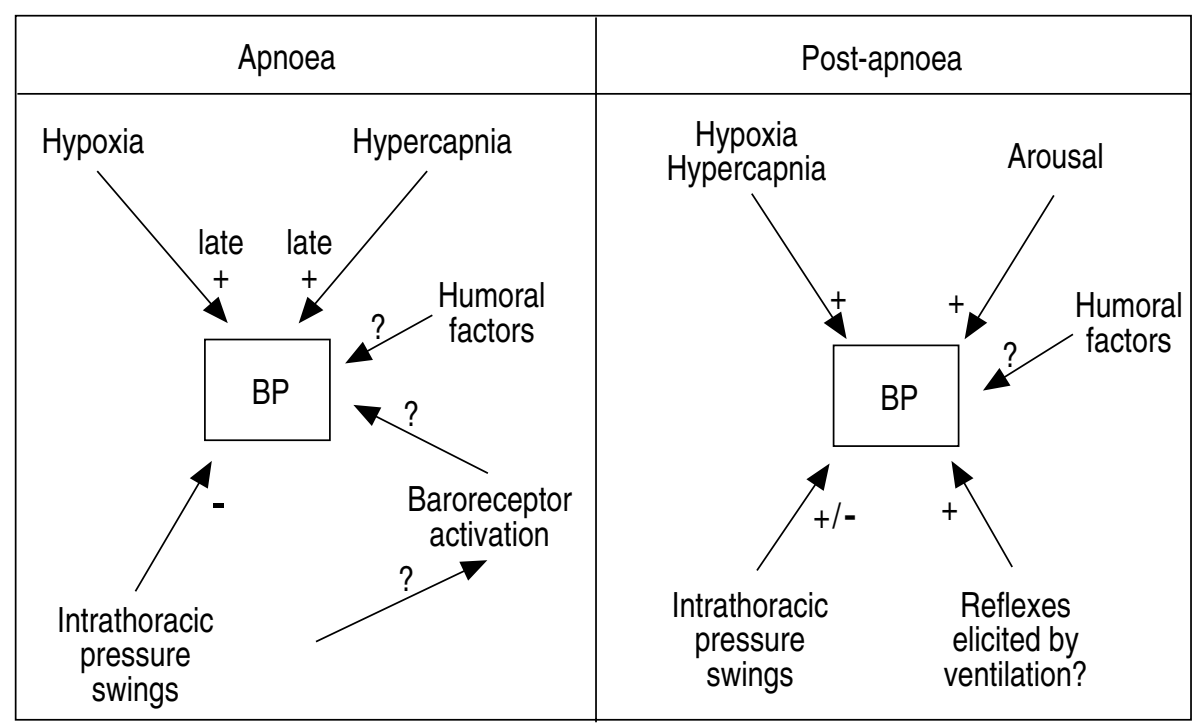

Fig. 6. - Schematic summary of the influence of various pathogenic factors on systemic arterial blood pressure (BP) during apnoeas and immediately post-apnoea (details in the text).

[29, 31]. In addition, this hypertensive response requires an intact autonomic nervous system, being absent in OSA patients with the Shy-Drager syndrome or transplanted heart [77, 126]. Various factors appear to contribute to its pathogenesis (fig. 6): hypoxia and hypercapnia, the arousal reaction, and OSA-induced changes in sympathoadrenal activity. However, the relative role of each of these possible causes is controversial.

The BP response to hypoxia is mediated by the activation of the carotid body $[67,68]$ and by SNA. In awake normal subjects, hypoxia increased muscle SNA, in turn causing peripheral vasoconstriction [139], while baroreceptor activation, at least partly, counteracted these hypertensive effects [140]. Hypoxia increased BP during both breathhold and ventilation [141, 142], despite SNA inhibition by ventilation [139]. During OSA, the relatively small and delayed BP increase of the apnoeic phase appears similar to the slow BP rise during breathholding [141], modified by the beat-by-beat oscillations dependent on the obstructed respiratory efforts [101]. During post-apnoea, the brisk BP peak may still be an effect of hypoxia, potentiated, however, by the arousal reaction $[11,143]$, or by a yet undefined reflex elicited by the resumption of ventilation [103, 126]. Several data support a role for hypoxia during post-apnoea. Firstly, oxygen desaturation during OSA is universally found to correlate with the post-apnoeic BP increase, although the slope of this relationship is highly variable among OSA patients [91]. Secondly, the increase in BP was prevented by oxygen administration in a human model of recurrent apnoeas during wakefulness [144], and in experimental studies mimicking OSA in dogs [39]. Thirdly, observations during sleep at high altitude indicated that periodic breathing is characterized by a fall in $\mathrm{SaO}_{2}$ and an increase in BP synchronous with breathing (Insalaco, unpublished observations) (fig. 7). A similar pattern was described in a patient with central alveolar hypoventilation and nocturnal periodic breathing [145].

Although these observations favoured a major role for hypoxia, the results of other studies gave rise to different conclusions. BP increased similarly during NREM OSA whether the patients were breathing room air or oxygen-enriched air to maintain $\mathrm{SaO}_{2} \geq 90 \%$ [146]. Conversely, BP did not change when the same patients breathed a hypoxic mixture under nCPAP $\left(\mathrm{SaO}_{2}\right.$ at $80 \%$ but no apnoeas) [146]. These results suggest that hypoxia was not the only cause of OSA-induced systemic hypertension. Such a conclusion, however, was recently questioned, because the flow of oxygen administered was relatively low, and perhaps insufficient to prevent the BP increase [39]. Another study compared BP during OSA while the patients were breathing room air, oxygenenriched air, or under nCPAP, and found similar mean or maximal BP values under the three conditions [147]. BP correlated with apnoea length and the maximal postapnoeic HR increase, suggesting that the arousal reaction at the end of OSA may be more important than hypoxia in the pathogenesis of the post-apnoeic BP peaks [147]. RingleR et al. [146] similarly reported that BP increased significantly after arousals. On the other hand, the increase in BP during nocturnal periodic ventilation at high altitude seemed to occur irrespective of EEG and electromyographic (EMG) signs of arousals (Insalaco, unpublished observations). Therefore, while results of some studies strongly support the hypertensive role of hypoxia, other studies point to the arousal reaction as an equally important cause of the nocturnal hypertensive peaks. Preliminary data comparing OSA and arousals in the same subjects have suggested that OSA-induced BP changes may differ in magnitude and time course from arousal-induced BP changes [143]. BP increased more in OSA than in isolated arousals [143]. In addition, BP increased after EEG changes in induced arousals, but before EEG changes during OSA, suggesting that arousals may potentiate the OSA-related effects of hypoxia [143].

It has long been known that BP increases during sleep after EEG arousals (K-complexes) [10, 39], and upon awakening [148]. However, the role of arousals as a 

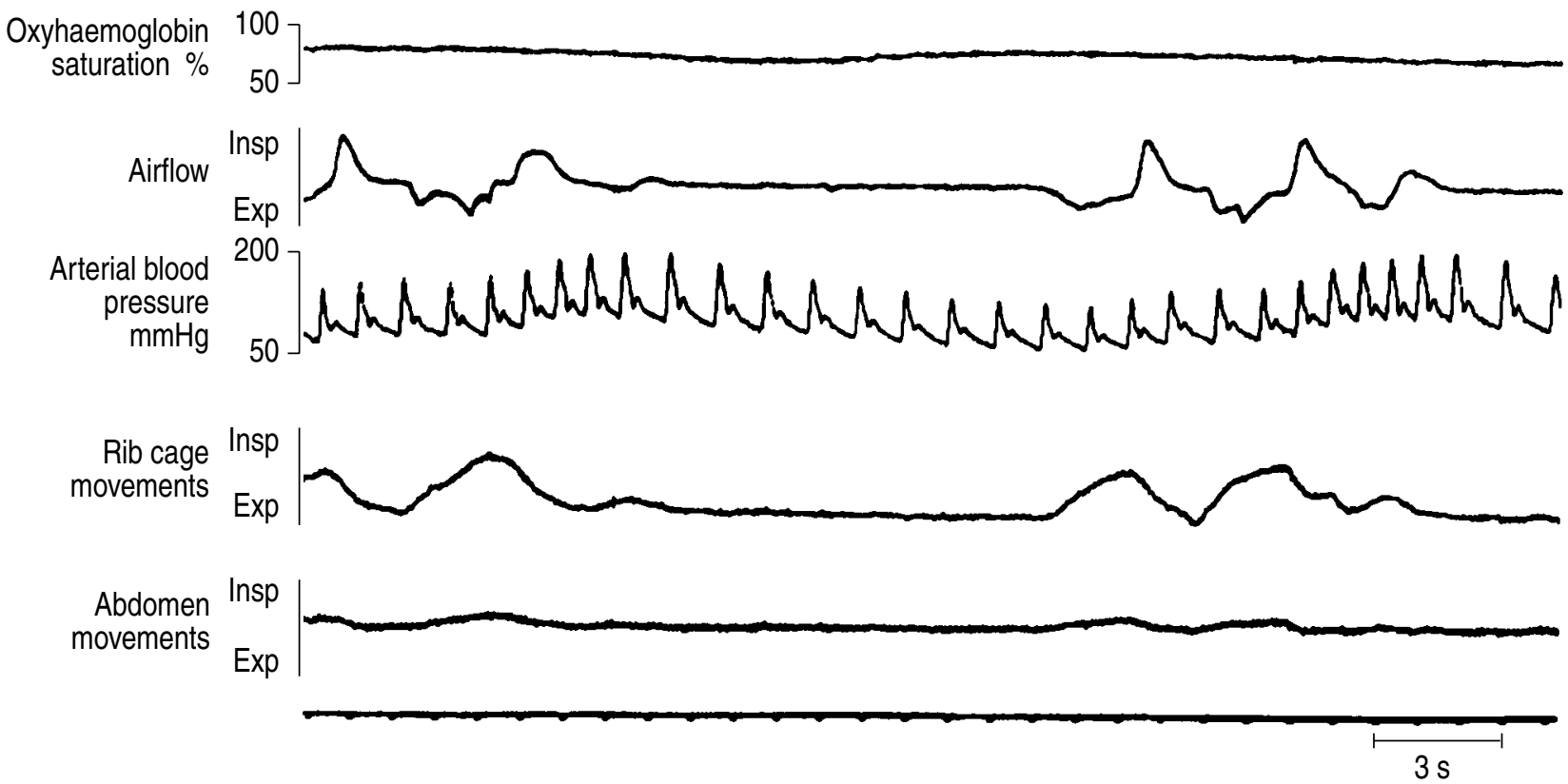

Fig. 7. - Periodic breathing during sleep at high altitude $(5,050 \mathrm{~m})$. Note the increase in systemic arterial blood pressure and heart rate during ventilation. Insp: inspiratory; Exp: expiration.

cause of BP changes has been reassessed recently by systematically analysing the cardiovascular response of normal subjects to graded arousal stimuli during sleep [11]. Changes in the EEG pattern were detected at $1 \mathrm{~s}$ intervals by computer analysis. As expected, arousal stimuli increased BP during both NREM and REM sleep, and usually caused EEG changes. However, stimuli insufficient to cause EEG changes also increased BP, suggesting that subcortical arousals may play an important role in OSAinduced cardiovascular changes, and that cardiovascular variables may be more sensitive indicators of sleep disruption than EEG [11]. The same group reported intriguing results in a patient with narcolepsy and periodic leg movements during sleep [149]. In this patient with no nocturnal hypoxaemia, BP increase coincided with arousals, but the BP changes during sleep persisted under temazepam treatment despite the disappearance of EEG signs of arousals [149]. Subcortical arousals may have been responsible for such BP changes, but this hypothesis should be substantiated before drawing any conclusion.

Concerning the mechanism by which arousals increase $\mathrm{BP}$, the sympathetic nervous system is believed to play a central role. When arousal stimuli were delivered to normal subjects, muscle SNA always increased before BP elevations during sleep but after EEG changes [10], leading to the conclusion that cortical activation is necessary for the cardiovascular response to arousals to occur [10]. These findings were in agreement with some data obtained in OSA patients [143], but not with the evidence of subcortical arousals provided by other investigators [11, 149]. The same arousal stimuli delivered during wakefulness, instead, evoked no cardiovascular response $[10,11]$. Methodological differences may explain the variability of results, for example concerning the type and intensity of the arousal stimuli used. However, a major cause of discrepancy could be that, despite the fact that scoring rules for EEG arousals have recently been published [150], criteria for the identification of very short arousals $(<3 \mathrm{~s}$ in duration) are still lacking. This field is in rapid evolution, and more definite data and criteria are to be expected in the future. In summary, the available results indicate that both hypoxia and arousals probably contribute to the pathogenesis of post-apnoeic hypertensive peaks. However, the role of arousals in OSA needs further clarification because, if arousals increase BP through increased SNA, this is hard to reconcile with the sudden decrease in muscle SNA described at the resumption of the ventilation after OSA [9]. One possibility is that arousals affect both skin and muscle SNA [52, 53], but no data are available at present on this issue.

The role of progressive hypercapnia in OSA-induced BP changes is traditionally considered minor compared to that of hypoxia, but experimental results on the cardiovascular effects of $\mathrm{CO}_{2}$ deserve some comment. Hypercapnia strongly potentiated the cardiovascular effect of hypoxia during both breathholding and ventilation [142], and the release of catecholamines induced by hypoxia $[151,152]$. Studies on muscle SNA, during either voluntary apnoea or ventilation with various gas mixtures in humans, confirmed the synergistic effect of hypoxia and hypercapnia in increasing SNA and BP [139, 153]. In addition, the increase in SNA and the hypertensive response to hypercapnia were insensitive to the feed-back mechanisms activated by the baroreceptor stimulation [140]. Instead, the increased SNA and the hypertensive response to hypoxia were selectively inhibited by baroreceptor stimulation [140]. Therefore, the role of hypercapnia in SNA and BP regulation during OSA, possibly overlooked compared to that of hypoxia [154], may be an important part of the cardiovascular response to OSA. 
Besides the increased SNA documented in OSA [9], increased catecholamine release, synergistically induced by hypoxia and hypercapnia [151, 152], may contribute to OSA-induced BP changes. Sleep fragmentation can also increase sympathoadrenal activity, since sympathetic blockade decreased BP more in REM-sleep-deprived rats than in controls [155]. Many groups have addressed the question of whether circulating or excreted catecholamines were affected by OSA [156-164]. Although most investigators agree on an increased catecholamine release in OSA patients, major differences were reported: most studies did not measure catecholamines in control subjects $[156,158,162]$, some reported only the changes observed under nCPAP therapy $[159,160,162]$, while the relationship between catecholamine release and the severity of sleep respiratory disturbances was variable [158, 160, 161, 164]. Concerning OSA-related acute BP changes, no correlation between nocturnal $\mathrm{BP}$ and catecholamine release was demonstrated [158, 164]. These results, together with the variable reports on the effects of nCPAP on catecholamine levels, do not allow for a definite role to be attributed to catecholamines in the pathogenesis of OSA-induced BP changes. Nevertheless, they emphasize that sympathoadrenal function is heightened in OSA, in agreement with the increased SNA shown in OSA patients not only during the night, but also during the daytime [9].

In addition, OSA may modify the release of other humoral factors exerting cardiovascular effects directly, or through changes in renal function and water-electrolyte homeostasis. Several studies have tested this hypothesis by measuring in OSA patients, both under baseline condition and during nCPAP, urinary flow and electrolytes [165], haematocrit [166, 167], proteinuria and albuminuria [168], plasma renin activity (PRA) and aldosterone [169-171], atrial natriuretic peptide (ANP) [172], and metabolites of thromboxane and prostacyclin [173]. In summary, their results indicate that urine output and electrolyte excretion are increased in OSA patients during sleep [165], probably via an augmented ANP release related to OSA-induced hypoxaemia and mechanical changes [172]. Increased haematocrit [166, 167] and low PRA $[169,170]$ indicated redistribution of liquids between the intra- and extravascular compartments, but circadian changes in PRA and aldosterone secretion were also demonstrated [171]. None of these complex alterations, however, was found to be directly related to OSAdependent BP changes, although the release of ANP may exert a protective role against the development of systemic hypertension by promoting sodium excretion [172]. Interestingly, the ratio between urinary 6-keto prostaglandin $\mathrm{F}_{1 \alpha}\left(\mathrm{PGF}_{1 \alpha}\right)$ and thromboxane- $\mathrm{B}_{2}$, the stable metabolites of prostacyclin and thromboxane- $\mathrm{A}_{2}$, respectively, increased under nCPAP, suggesting that release of vasoconstrictor prostaglandins may predominate in untreated OSA [173]. However, no correlation was found between this ratio and OSA severity or BP [173]. Arachidonic acid metabolites may affect the response to sympathetic stimulation, since the progressive increase in BP during repeated cold pressor test in humans could be related to reduced release of vasodilator prostaglandins [174]. These results, together with the relative decrease in the production of prosta- cyclin found in OSA [173], suggest that arachidonic acid metabolites might intervene in modulating OSA-induced BP changes.

\section{The role of OSA in diurnal pulmonary hypertension (fig. 8)}

Since the first studies on OSA, it was hypothesized that the pulmonary hypertensive peaks continuously recurring during sleep may evolve into stable pulmonary hypertension [126]. This hypothesis was not confirmed, since right heart failure [175] or increased PAP during wakefulness $[176,177]$ were only found in a minority of OSA patients with diurnal hypoxaemia and/or hypercapnia. Nevertheless, although insufficient to independently cause pulmonary hypertension, OSA potentiated the pulmonary vascular effects of COPD in the "overlap syndrome" [178]. Right heart failure or pulmonary hypertension were found to develop at modest degrees of airway obstruction in the presence of OSA [175-177]. To account for the diurnal hypoxaemia often found in OSA patients, other possible pathogenic factors were investigated. Most studies failed to find a significant relationship between the severity of OSA and pulmonary hypertension [175-177], and suggested that obesity, causing a restricted ventilatory pattern, and/or reduced chemosensitivity with hypoventilation, may be responsible for daytime hypoxaemia and pulmonary hypertension in OSA patients. Conversely, KRIEGER et al. [179], while confirming the importance of impaired pulmonary function, found that the severity of OSA did contribute to the pathogenesis of daytime pulmonary hypertension, hypoxaemia and hypercapnia. However, treatment of OSA, either by tracheostomy [176] or long-term nCPAP [180], did not decrease diurnal PAP significantly, even when arterial blood gases improved [180]. The lack of statistical significance could be due to the small number of pulmonary hypertensive patients studied [176, 180]. Alternatively, treatment of OSA may act by preventing further increases in PAP, rather than by decreasing already elevated PAP levels [180]. Preliminary data suggest that some OSA patients may show a heightened pulmonary vascular responsiveness to hypoxia and hypercapnia, which may return to normal with long-term nCPAP [181].

Concerning the role of OSA in the development of right ventricular hypertrophy, controversial results have been reported so far. BERMAN et al. [182] found echocardiographic evidence of right ventricular hypertrophy in $71 \%$ of their unselected OSA patients. In another preliminary study, increased RV wall thickness and abnormal filling correlated to the severity of sleep-related respiratory disturbances [183]. HaNLY et al. [118] found no evidence of right ventricular enlargement in snorers with or without OSA. These opposing conclusions may result from differences in the patients studied or in methods [184].

However, other factors could be involved in the pathogenesis of right ventricular hypertrophy. For example, genetic susceptibility may play some role, since it was reported that right ventricular hypertrophy developed in SpragueDawley rats, but not in Wistar rats, exposed to repeated intermittent hypoxia [40]. In addition, the chronic effects 


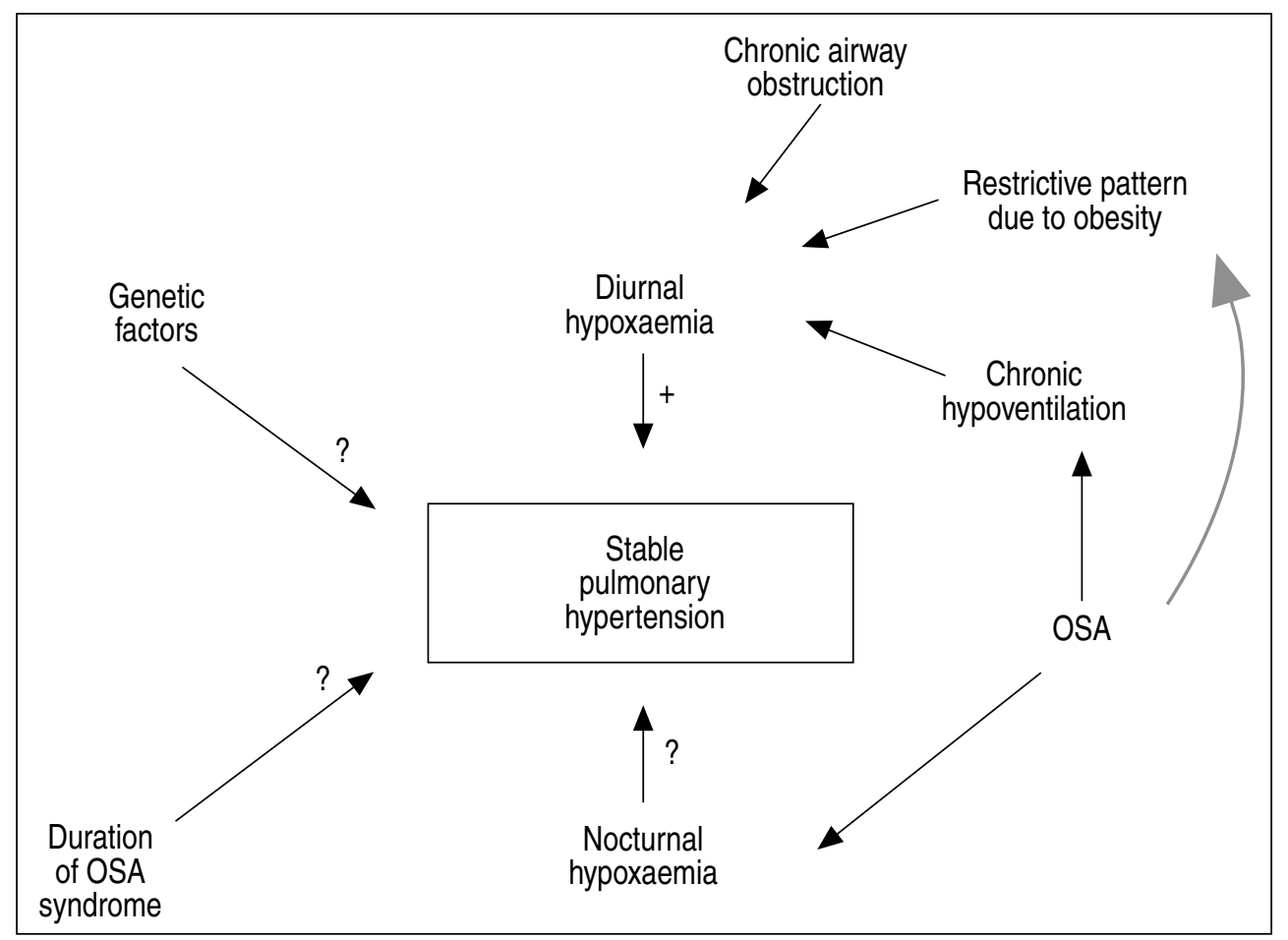

Fig. 8. - Schematic summary of the influence of various pathogenic factors in causing stable pulmonary hypertension in patients with the obstructive sleep apnoea (OSA) syndrome. The association between OSA and obesity is indicated by a hatched arrow (details in the text).

of OSA-dependent mechanical changes on the pulmonary circulation and on the right ventricle are unknown [179]. To summarize, there is general agreement that OSA does potentiate the effects of concomitant lung disease, whereas there is no conclusive proof that it independently causes stable pulmonary hypertension and/or right ventricular hypertrophy.

\section{The role of OSA in diurnal systemic hypertension (fig. 9)}

The hypothesis that OSA may favour the development of stable hypertension (HT) was advanced since the first studies in OSA patients [97], and was supported by the high prevalence of HT in OSA found by most, if not all, investigators [18, 21, 77, 134, 185-187]. In addition, it is possible that at least some hypertensive OSA patients become normotensive after tracheostomy [77, 176, 188190] or nCPAP [33, 191], although some time may be necessary for OSA therapy to normalize BP. Even during sleep, nCPAP acutely decreased systolic BP, but did not affect diastolic BP in any sleep stage [192].

In order to understand the role of sleep-related respiratory disturbances in the pathogenesis of HT, the relationship between BP and snoring was examined [16, 22, 23, 187, 193-199], with variable results. Snoring was found to be directly related to diurnal [23] or nocturnal HT [134, 198], but most studies suggested that this relationship was indirect, mediated by age, cigarette smoking, or obesity [16, 22, 129, 187, 193, 194, 196, 197, 199, 200]. Prevalence of snoring was mostly assessed by questionnaire, and these results should be considered as only suggestive of an association between snoring and increased BP [26].
In studies on the relationship between nocturnal hypoxaemia and HT in snorers, obesity was found to be the factor most likely to be responsible for both snoring and nocturnal oxygen desaturations $[16,129,194,196]$, whereas the number of sleep-disordered breathing events and/or the degree of nocturnal hypoxaemia did not predict HT [187]. In OSA patients, obesity correlated strongly with HT [18, 187], even after chronic nCPAP therapy [201]. However, the issue is still unresolved, as some studies found that sleep-disordered breathing may contribute to HT in OSA patients [21, 196], even more than obesity [202]. On the other hand, no difference in sleep architecture, apnoea index, $\mathrm{SaO}_{2}$ indices, or number of arousals was found between normotensive and hypertensive OSA patients [185].

The arguments in favour and against a role of OSA in the pathogenesis of HT were extensively reviewed [15, 17-20, 30, 33, 34], but no definite conclusion is presently available. A high prevalence of OSA was reported in hypertensive patients, although the degree of sleeprelated respiratory disturbances in essential HT appeared low [12-14, 203-206]. Recent data have challenged the previously reported high prevalence of OSA in hypertensive patients, by reporting very few episodes of nocturnal hypoxaemia in a sample of such patients compared to age- and body mass index-matched controls [207]. The studies on hypertensive patients also left some questions unanswered, in particular on the possible role of the antihypertensive treatment in the pathogenesis of OSA [20].

Despite the unresolved controversies, it is conceivable that OSA and HT might share common pathogenic factors (fig. 9). More specifically, it was recently proposed that abnormalities of the autonomic responses to 


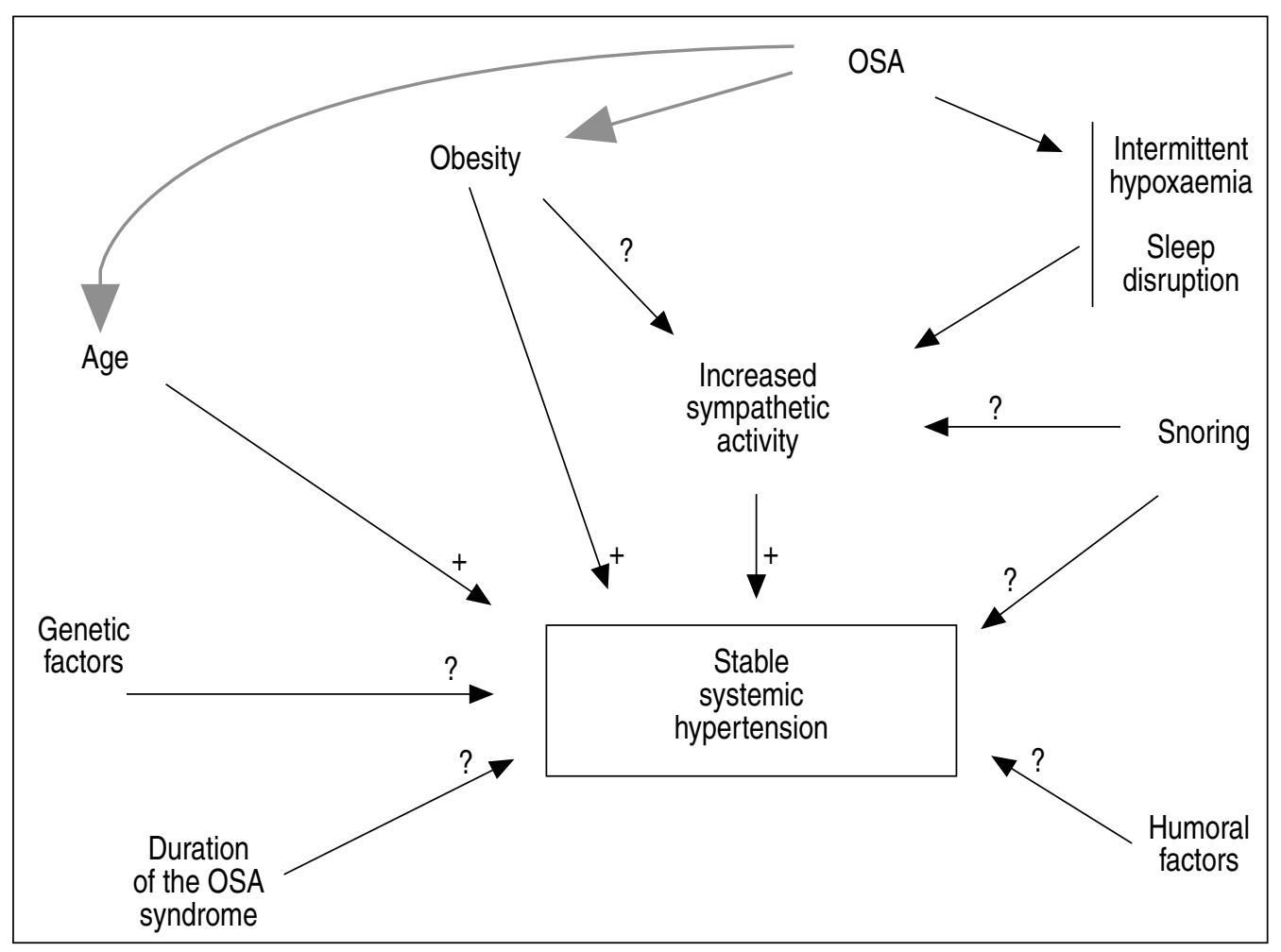

Fig. 9. - Schematic summary of the influence of various pathogenic factors in causing stable systemic hypertension in patients with the obstructive sleep apnoea (OSA) syndrome. The association between OSA and obesity or age is indicated by a hatched arrow (details in the text).

hypoxia [208] may be the link between OSA and essential HT [154]. Enlargement of the carotid body is commonly found in both essential HT and chronic hypoxia [209], but the anatomical features of the carotid bodies in OSA patients are unknown, as are the cellular mechanisms of carotid chemotransduction [3, 210]. However, hypoxia by itself does not appear to exert a strong hypertensive effect, since prevalence of HT is much higher in OSA patients than in patients with restrictive lung disease with comparable nocturnal falls in $\mathrm{SaO}_{2}$ [211].

The evidence suggesting an abnormal chemoreceptor function in OSA and HT comes from different studies reporting variable results. Thus, the pathogenic role of altered chemotransduction is still an open question. In addition, there is no consensus on the abnormal cardiovascular and/or ventilatory response to hypoxia in both conditions. It was recently reported that OSA patients, either normotensive or hypertensive, develop a hypertensive response to hypoxia during wakefulness [212]. Such response, absent in controls, correlated with indices of severity of OSA, but not with daytime BP. However, no pressor response to hypoxia was found in another study on normotensive OSA patients [211].

The study reporting a significant pressor response to hypoxia in OSA patients found that, although the pressor and ventilatory responses were significantly related in the group of patients, they were found to be uncoupled in some cases [212]. The ventilatory response to hypoxia was reported to be decreased in normotensive OSA patients, possibly in relation to their increased upper airway resistance [213], whereas another study found that it was higher in hypertensive than in normotensive OSA patients [214]. On the other hand, breathing 100\% oxygen normally depressed ventilation in normotensive OSA patients, but had no effect on BP [213].

In borderline HT, hypoxia increased SNA, especially during breathholding, indicating an enhanced chemoreceptor reflex [215], whereas variable results were reported concerning the effect of hypoxia on ventilation [215, 216]. In patients with HT, breathing $100 \%$ oxygen decreased both ventilation and BP, indicating an increased resting ventilatory and circulatory chemoreceptor drive [213]. The ventilatory response to hypoxia was found to be increased in young hypertensives (age 20-41 yrs) but not in older groups [213]. These variable results, while supporting the hypothesis of an involvement of the carotid body in both OSA and HT, are far from conclusively proving any cause-effect relationship.

Support for the hypothesis that OSA may cause stable HT comes from experimental data obtained in carefully controlled studies in rats $[41,217,218]$. Repeated episodic hypoxia progressively increased BP [40], through activation of the carotid chemoreceptors [217] and increased SNA [218]. These experiments underlined that the intermittent occurrence of hypoxia may be the main factor in the pathogenesis of stable HT. Continuous hypoxia causes vasodilation, not vasoconstriction [40, 219], possibly explaining why stable HT is more common clinically in OSA patients than in patients with chronic pulmonary disease [211].

Intriguing results have been reported on the myocardial effects of hypoxia. Development of left ventricular 
hypertrophy during hypoxia [220] occurred independent of HT in carotid body-denervated [217] or sympatheticdenervated [218] rats, suggesting that the myocardial effect of hypoxia might be direct, not through increased BP levels. These data may confirm the clinical finding that left ventricular hypertrophy is often found in OSA patients, irrespective of the presence of HT, and cannot be completely explained as an effect of obesity [221]. Persistently increased SNA [9] or the nocturnal hypertensive BP peaks [221] could partly account for it, but no correlation was found between left ventricular mass and severity of OSA [221]. These data were not confirmed by another study [117], but the possible effect of hypoxia on the myocardium deserves further investigation.

The link between OSA and HT could be through an increased sympathetic responsiveness. Persistently increased muscle SNA was demonstrated in OSA patients [9], and in essential HT [215]. Since increased SNA may mediate the effects of metabolic abnormalities, like hyper-insulinaemia [222], a direct or indirect role of obesity in both OSA and HT can be hypothesized [201]. Among other mechanisms by which OSA may contribute to the pathogenesis of HT, experimental data showed that REM sleep deprivation in rats affected sleep-dependent BP changes [223], but caused sustained HT only in rats with partial genetic predisposition to HT [155]. In humans, some relatives of hypertensive patients showed abnormal ventilatory responses to hypoxia or hyperoxia, whereas relatives of OSA patients responded normally to the same stimuli [213]. This field is mostly unexplored, but, as a possible hypothesis, genetic factors may be as important as hypoxia in the development of HT in OSA.

\section{The "big picture"}

What conclusions are possible on the pathogenesis of the acute and chronic cardiovascular changes commonly observed in OSA patients? This review of the literature indicates that despite the large amount of work already done, many questions are still unanswered, especially on the pathogenesis of OSA-induced chronic systemic hypertension. Instead, a "big picture" can at least be delineated for the acute haemodynamic changes occurring during sleep in OSA patients. We believe that such changes recognize a different pathogenesis according to the phase of the apnoeic cycle in which they occur (figs 1, 2, 6 and 7). During the apnoeic phase, the most impressive cardiovascular changes are determined by the mechanical effects of airway obstruction, whereas during the interapnoeic periods the role of chemical factors (hypoxia, hypercapnia) and of arousals, both acting through a complex activation of reflex circulatory adjustments, seems major compared to the role of mechanical effects. Interestingly, the pulmonary and systemic circulations are similarly affected by OSA, supporting the hypothesis that OSA may elicit generalized reflex changes. Another interesting point emerging from the available literature is that pulmonary inflation, commonly held as exerting a negative feed-back control on cardiovascular changes evoked by hypoxia, seems to exert a permissive role during OSA, since the most dramatic hypertensive peaks occur at the resumption of the ventilation, and are coupled with a transient decrease in aortic and pulmonary flow. It is possible that lung volume changes temporally coincide with the effects of other factors, for example, the arousal reaction, but this hypothesis has not yet been tested. In addition, the large amount of data recently collected on SNA during sleep has mostly concerned muscle SNA, whereas analysis should include other areas, like the skin, in an effort to gain a comprehensive view of the entire sympathetic nervous system activity during OSA.

Concerning chronic cardiovascular changes in OSA patients, the "big picture" seems quite well drawn for the pathogenesis of stable pulmonary hypertension (fig. 8). Nevertheless, our limited knowledge of the natural history of the OSA syndrome warrants further longitudinal studies. At present, only a tentative scheme can be drawn on the pathogenesis of stable systemic hypertension (fig. 9), although the hypothesis of an abnormal chemoreceptor response to hypoxia seems very promising.

\section{References}

1. Andersen H. Physiological adaptations in diving vertebrates. Physiol Rev 1966; 46: 212-243.

2. Scharf S. Cardiovascular effects of airways obstruction. Lung 1991; 169: 1-23.

3. Eyzaguirre C, Fitzgerald R, Lahiri S, Zapata P. Arterial chemoreceptors. In: Shepherd J, Abboud F, eds. Handbook of Physiology: The Cardiovascular System. Bethesda, MD, American Physiological Society, 1983; pp. 557-621.

4. Phillipson E, Sullivan C, Read D, Murphy E, Kozar L. Ventilatory and waking responses to hypoxia in sleeping dogs. J Appl Physiol: Respirat Environ Exercise Physiol 1978; 44: 512-520.

5. Neubauer J, Santiago T, Edelman N. Hypoxic arousal in intact and carotid chemodenervated sleeping cats. $J$ Appl Physiol: Respirat Environ Exercise Physiol 1981; 51: 1294-1299.

6. Mancia G, Baccelli G, Adams D, Zanchetti A. Vasomotor regulation during sleep in the cat. Am J Physiol 1971; 220: 1086-1093.

7. Franzini C, Cianci T, Lenzi P, Guidalotti P. Neural control of vasomotion in rabbit ear is impaired during desynchronized sleep. Am J Physiol 1982; 243: R142-R146.

8. Baust W, Bohnert B. The regulation of heart rate during sleep. Exp Brain Res 1969; 7: 169-180.

9. Hedner J, Ejnell H, Sellgren J, Hedner T, Wallin G. Is high and fluctuating muscle nerve sympathetic activity in the sleep apnea syndrome of pathogenic importance for the development of hypertension? J Hypertension 1988; 6: S529-S531.

10. Shimizu T, Takahashi Y, Suzuki K, et al. Muscle nerve sympathetic activity during sleep and its change with arousal response. J Sleep Res 1992; 1: 178-185.

11. Davies R, Belt P, Roberts S, Ali N, Stradling J. Arterial blood pressure responses to graded transient arousal from sleep in normal humans. J Appl Physiol 1993; 74: 1123-1130.

12. Lavie P, Ben-Yosef R, Rubin A. Prevalence of sleep apnea syndrome among patients with essential hypertension. Am Heart J 1984; 108: 373-376.

13. Fletcher E, DeBehnke R, Lovoi M, Gorin A. Undiagnosed 
sleep apnea in patients with essential hypertension. Ann Intern Med 1985; 103: 190-195.

14. Williams A, Houston D, Finberg S, Lam C, Kinney J, Santiago S. Sleep apnea syndrome and essential hypertension. Am J Cardiol 1985; 55: 1019-1022.

15. Stradling J. Sleep apnea and systemic hypertension. Thorax 1989; 44: 984-989.

16. Stradling J, Crosby J. Relation between systemic hypertension and sleep hypoxemia or snoring: analysis in 748 men drawn from general practice. $\mathrm{Br}$ Med $J$ 1990; 300: 75-78.

17. Krieger J, Imbs J. Role des apnées du sommeil dans l'hypertension artérielle essentielle. Presse Méd 1990; 19: 1805-1809.

18. Millman R, Redline S, Carlisle C, Assaf A, Levinson P. Daytime hypertension in obstructive sleep apnea. Prevalence and contributing risk factors. Chest 1991; 99: 861866.

19. Hoffstein V, Chan C, Slutsky A. Sleep apnea and systemic hypertension: a causal association review. Am J Med 1991; 91: 190-196.

20. Stradling J. Systemic hypertension and sleep apnoea. In: Gaultier C, Escourrou P, Curzi-Dascalova L, eds. Sleep and cardiorespiratory control. Montrouge, France, Colloque INSERM/John Libbey Eurotext Ltd, 1991; pp. 115-122.

21. Mendelson W. Sleepiness and hypertension in obstructive sleep apnea. Chest 1992; 101: 903-909.

22. Lugaresi E, Cirignotta F, Coccagna G, Piana C. Some epidemiological data on snoring and cardiocirculatory disturbances. Sleep 1980; 3: 221-224.

23. Koskenvuo M, Kaprio J, Partinen M, Langinvainio H, Sarna S, Heikkilä K. Snoring as a risk factor for hypertension and angina pectoris. Lancet 1985; i: 893-896.

24. Koskenvuo M, Kaprio J, Telakivi T, Partinen M, Heikkilä $\mathrm{K}$, Sarna S. Snoring as a risk factor for ischemic heart disease and stroke in men. Br Med J 1987; 294: 16-19.

25. Partinen M, Palomäki H. Snoring and cerebral infarction. Lancet 1985; ii: 1325-1326.

26. Waller P, Bhopal R. Is snoring a cause of vascular disease? An epidemiological review. Lancet 1989; i: 143-146.

27. Zaninelli A, Fariello R, Boni E, Corda L, Alicandri C, Grassi V. Snoring and risk of cardiovascular disease. Int J Cardiol 1991; 32: 347-352.

28. Young T, Palta M, Dempsey J, Skatrud J, Weber S, Badr $\mathrm{S}$. The occurrence of sleep-disordered breathing among middle-aged adults. N Engl J Med 1993; 328: 1230-1235.

29. Shepard JR Jr. Hemodynamics in Obstructive Sleep Apnea. In: Fletcher EC, eds. Abnormalities of Respiration during sleep. Grune \& Stratton, Inc. Orlando, FL, 1986; pp. 39-61.

30. Levinson P, Millman R. Causes and consequences of blood pressure alterations in obstructive sleep apneas. Arch Intern Med 1991; 151: 455-462.

31. Parish J, Shepard JR Jr. Cardiovascular effects of sleep disorders. Chest 1990; 97: 1220-1226.

32. Messner-Pellenc P. Troubles cardio-vasculaires au cours du sommeil. Presse Méd 1990; 19: 1851-1856.

33. Guilleminault C, Suzuki M. Sleep-related hemodynamics and hypertension with partial or complete upper airway obstruction during sleep. Sleep 1992; 15: S20-S24.

34. Shepard JR Jr. Hypertension, cardiac arrhythmias, myocardial infarction, and stroke in relation to obstructive sleep apnea. Clin Chest Med 1992; 13: 437-458.

35. Bradley T. Right and left ventricular function impairment and sleep apnea. Clin Chest Med 1992; 13: 459-479.

36. Rosen R, Rosekind M, Rosevear C, Cole W, Dement W.
Physician education on sleep and sleep disorders: A National survey of US Medical Schools. Sleep 1993; 16: 249-254.

37. Parati G, Pomidossi G, Casadei R, et al. Ambulatory blood pressure monitoring does not interfere with the hemodynamic effects of sleep. J Hypertension 1985; 3: S107-S109.

38. Hendricks C, Kowalsky R, Kline L. Phasic respiratory muscle patterns and sleep-disordered breathing during rapid eye movement sleep in the English bulldog. Am Rev Respir Dis 1991; 144: 1112-1120.

39. Iwase N, Kikuchi Y, Hida W, et al. Effects of repetitive airway obstruction on $\mathrm{O}_{2}$ saturation and systemic and pulmonary arterial pressure in anesthetized dogs. Am Rev Respir Dis 1992; 146: 1402-1410.

40. Fletcher E, Lesske J, Qian W, Miller CC III, Unger T. Repetitive episodic hypoxia causes diurnal elevation of blood pressure in rats. Hypertension 1992; 20: 555-561.

41. O'Donnell C, King E, Robotham J, Schwartz A, Smith P. A chronic dog model to study the cardiovascular effects of repetitive airway obstruction. Am Rev Respir Dis 1993; 147: A1016.

42. Somers V, Dyken M, Mark A, Abboud F. Sympatheticnerve activity during sleep in normal subjects. $N$ Engl $J$ Med 1993; 328: 303-307.

43. Snyder F, Hobson J, Morrison D, Goldfrank F. Changes in respiration, heart rate and systolic blood pressure in human sleep. J Appl Physiol 1964; 19: 417-422.

44. Khatri I, Freis E. Hemodynamic changes during sleep. J Appl Physiol 1967; 22: 867-873.

45. Lugaresi E, Coccagna $\mathrm{G}$, Cirignotta $\mathrm{F}$, et al. Breathing during sleep in man in normal and pathological conditions. Adv Exp Med Biol 1978; 99: 33-45.

46. Bristow J, Honour A, Pickering T, Sleight P. Cardiovascular and respiratory changes during sleep in normal and hypertensive subjects. Cardiovasc Res 1969; 3: 476-485.

47. Littler W, Honour A, Carter R, Sleight P. Sleep and blood pressure. Br Med J 1975; 3: 346-348.

48. Degaute J-P, van den Borne P, Linkowski P, Cauter EV. Quantitative analysis of the 24 hour blood pressure and heart rate patterns in young men. Hypertension 1991; 18: 199-210.

49. Wallin B. Human sympathetic nerve activity during normal sleep and in sleep apnoea. In: Gaultier C, Escourrou P, Curzi-Dascalova L, eds. Sleep and Cardiorespiratory Control. Montrouge, France, Colloque INSERM/John Libbey Eurotext Ltd, 1991; pp. 73-78.

50. Laguzzi R. Cardiovascular changes during the sleepwake cycle. In: Gaultier C, Escourrou P, Curzi-Dascalova L, eds. Sleep and Cardiorespiratory Control. Montrouge, France, Colloque INSERM/John Libbey Eurotext Ltd, 1991; pp. 9-13.

51. Hornyak M, Cejnar M, Elam M, Matousek M, Wallin B. Sympathetic muscle nerve activity during sleep in man. Brain 1991; 114: 1281-1295.

52. Vallbo A, Hagbarth K, Torebjörk H, Wallin B. Somatosensory, proprioceptive, and sympathetic activity in human peripheral nerves. Physiol Rev 1979; 59: 919-957.

53. Goldman M, Casey K, Jones C. Cardiorespiratory autonomic reflex behaviour during sleep. In: Gaultier C, Escourrou P, Curzi-Dascalova L, eds. Sleep and Cardiorespiratory Control. Montrouge, France, Colloque INSERM/John Libbey Eurotext Ltd, 1991; pp. 87-94.

54. Sindrup J, Kastrup J, Madsen P, Christensen H, Jørgensen B, Wildschiødtz G. Nocturnal variations in human lower 
leg subcutaneous blood flow related to sleep stages. $J$ Appl Physiol 1992; 73: 1246-1252.

55. Townsend R, Prinz P, Obrist W. Human cerebral blood flow during sleep and waking. J Appl Physiol 1973; 35: 620-625.

56. Sawaya R, Ingvar D. Cerebral blood flow and metabolism in sleep. Acta Neurol Scand 1989; 80: 481-491.

57. Fischer A, Chaundary B, Taormina M, Akhtar B. Intracranial hemodynamics in sleep apnea. Chest 1992; 102: 1402-1406.

58. Parati G, Rienzo MD, Bertinieri G, et al. Evaluation of the baroreceptor-heart rate reflex by 24 hour intra-arterial blood pressure in humans. Hypertension 1988; 12: 214-222.

59. Libert J, Candas V, Muzet A, Ehrhart J. Thermoregulatory adjustments to thermal transients during slow wave sleep and REM sleep in man. J Physiol (Paris) 1982; 78: 251-257.

60. Mancia G. Autonomic modulation of the cardiovascular system during sleep. N Engl J Med 1993; 328: $347-$ 349.

61. Guilleminault C, Connolly S, Winkle R, Melvin K, Tilkian A. Cyclical variation of the heart rate in sleep apnoea syndrome. Lancet 1984; i: 126-131.

62. Coccagna G, Mantovani M, Brignani F, Parchi C, Lugaresi E. Continuous recording of the pulmonary and systemic arterial pressure during sleep in syndromes of hypersomnia with periodic breathing. Bull Eur Physiopathol Respir 1972; 8: 1159-1172.

63. Zwillich C, Devlin T, White D, Douglas N, Weil J, Martin R. Bradycardia during sleep apnea. Characteristics and mechanisms. J Clin Invest 1982; 69: 1286-1292.

64. Angell-James J, Daly M. Cardiovascular responses in apnoeic asphyxia: role of arterial chemoreceptors and the modification of their effects by a pulmonary vagal inflation reflex. $J$ Physiol 1969; 201: 87-104.

65. Lin Y, Shida K, Hong S. Effects of hypercapnia, hypoxia, and rebreathing on heart rate response during apnea J Appl Physiol: Respirat Environ Exercise Physiol 1983; 54: 166-171.

66. Findley L, Farkas G, Rochester D. Changes in heart rate during breathing interrupted by recurrent apneas in humans. J Appl Physiol 1985; 59: 536-542.

67. Lugliani R, Whipp B, Wasserman K. A role for the carotid body in cardiovascular control in man. Chest 1973; 63: 744-750.

68. Honda Y. Respiratory and circulatory activities in carotid body-resected humans. $J$ Appl Physiol 1992; 73: 1-8.

69. Downing S, Mitchell J, Wallace A. Cardiovascular responses to ischemia, hypoxia, and hypercapnia of the central nervous system. Am J Physiol 1963; 204: 881887.

70. Escourrou P, Gros VL, Gaultier C. Baroreflex control of heart rate in sleep apnea patients. In: Gaultier C, Escourrou P, Curzi-Dascalova L, eds. Sleep and Cardiorespiratory Control. Montrouge, France, Colloque INSERM/J Libbey Eurotext Ltd, 1991; pp. 193-201.

71. Hanly P, George C, Millar T, Kryger M. Heart rate response to breathhold, Valsalva and Mueller maneuvers in obstructive sleep apnea. Chest 1989; 95: 735-739.

72. Andreas S, Hajak G, Breska B, Rüther E, Kreuzer H. Changes in heart rate during obstructive sleep apnoea. Eur Respir J 1992; 5: 853-857.

73. Katona P, Jih F. Respiratory sinus arrhythmia: noninvasive measure of parasympathetic cardiac control. J Appl Physiol 1975; 39: 801-805.

74. Bonsignore M, Marrone O, Romano S. Respiratory sinus arrhythmia in obstructive sleep apneas. Eur Respir J 1993; 6(Suppl. 17): H67s.

75. Spyer K. Functional organization of cardiorespiratory control. In: Gaultier C, Escourrou P, Curzi-Dascalova L, eds. Sleep and Cardiorespiratory Control. Montrouge, France, Colloque INSERM/John Libbey Eurotext Ltd, 1991; pp. 3-8.

76. Stoohs R, Guilleminault C. Cardiovascular changes associated with obstructive sleep apnea syndrome. J Appl Physiol 1992; 72: 583-589.

77. Coccagna G, Cirignotta F, Lugaresi E. Changes in general circulation in sleep apnea syndrome. In: Peter J, Penzel T, Podszus T, von Wichert P, eds. Sleep and Health Risk. Berlin, Springer-Verlag, 1991; pp. 300-309.

78. Bonsignore M, Marrone O, Romano S, Pieri D. Time course of right ventricular stroke volume and output during obstructive sleep apneas. Am Rev Respir Dis 1993; (in press).

79. Guilleminault C, Tilkian A, Lehrman K, Forno Y, Dement W. - Sleep apnoea syndrome: states of sleep and autonomic dysfunction. J Neurol Neurosurg Psychiat 1977; 40: 718-725.

80. Coccagna G, Martinelli P, Zucconi M, Cirignotta F, Ambrosetto G. Sleep-related respiratory and hemodynamic changes in Shy-Drager syndrome: a case report. J Neurol 1985; 232: 310-313.

81. Akselrod S, Gordon D, Madwed J, Snidman N, Shannon D, Cohen R. Hemodynamic regulation: investigation by spectral analysis. Am J Physiol 1985; 249: H867-H875.

82. Pomeranz B, Macaulay R, Caudill M, et al. Assessment of autonomic function in humans by heart rate spectral analysis. Am J Physiol 1985; 248: H151-H153.

83. Curzi-Dascalova L, Clairambault J, Kauffmann F, Médigue C, Peirano P. Cardiorespiratory variability and development of sleep state organization. In: Gaultier C, Escourrou P, Curzi-Dascalova L, eds. Sleep and Cardiorespiratory Control. Montrouge, France, Colloque INSERM/J Libbey Eurotext Ltd, 1991; pp. 155-163.

84. Haddad G, Jeng H, Lee S, Lai T. Rhythmic variations in R-R interval during sleep and wakefulness in puppies and dogs. Am J Physiol 1984; 247: H67-H73.

85. Raetz S, Richard C, Garfinkel A, Harper R. Dynamic characteristics of cardiac R-R intervals during sleep and waking states. Sleep 1991; 14: 526-533.

86. Penzel T, Peter J, von Wichert P. Spectral analysis of heart rate and blood pressure in sleep apnea syndrome. In: Gaultier C, Escourrou P, Curzi-Dascalova L, eds. Sleep and Cardiorespiratory Control. Montrouge, France, Colloque INSERM/J Libbey Eurotext Ltd, 1991; pp. 79-85.

87. Karemaker J, Aardweg J. Low frequency oscillations in the cardiovascular system due to respiration: blood pressure variability in sleep apnoea syndrome. In: Di Rienzo M, Mancia G, Parati G, Pedotti A, Zanchetti A, eds. Blood Pressure and Heart Rate Variability. Amsterdam, IOS Press, 1993; pp. 252-257.

88. Ferini-Strambi L, Zucconi M, Oldani A, Smirne S. Heart rate variability during sleep in snorers with and without obstructive sleep apnea. Chest 1992; 102: 1023-1027.

89. Veale D, Pepin J, Lévy P. Autonomic stress tests in obstructive sleep apnea syndrome and snoring. Sleep 1992; 15: 505-513.

90. Tilkian A, Guilleminault C, Schroeder J, Lehrman K, Simmons F, Dement W. Sleep-induced apnea syndrome. Prevalence of cardiac arrhythmias and their reversal after tracheostomy. Am J Med 1977; 63: 348-358.

91. Shepard JR, Jr. Gas exchange and hemodynamics during sleep. Med Clin North Am 1985; 69: 1243-1263. 
92. Guilleminault C, Connolly S, Winkle R. Cardiac arrhythmia and conduction disturbances during sleep in 400 patients with sleep apnea syndrome. Am J Cardiol 1983; 52: 490-494.

93. Alford N, Fletcher E, Nickeson D. Acute oxygen in patients with sleep apnea and COPD. Chest 1986; 89: 30-38.

94. Loeppky L, Miranda F, Eldridge M. Abnormal cerebrovascular responses to $\mathrm{CO}_{2}$ in sleep apnea patients. Sleep 1984; 7: 97-109.

95. Hajak G, Klingerhöfer J, Schulz-Varszegi M, Matzander G, Conrad B, Rüther E. Stroke mechanisms in sleep. $J$ Sleep Res 1992; 1: 90.

96. Levy P, Guilleminault C, Fagret D, et al. Changes in left ventricular ejection fraction during REM sleep and exercise in chronic obstructive pulmonary disease and sleep apnoea syndrome. Eur Respir J 1991; 4: 347352.

97. Tilkian A, Guilleminault C, Schroeder J, Lehrman K, Simmons F, Dement W. Hemodynamics in sleep-induced apnea. Studies during wakefulness and sleep. Ann Intern Med 1976; 85: 714-719.

98. Podszus T, Mayer J, Penzel T, Peter J, von Wichert P. - Nocturnal hemodynamics in patients with sleep apnea. Eur J Respir Dis 1986; 69: 435-442.

99. Guilleminault C, Motta J, Mihm F, Melvin K. Obstructive sleep apnea and cardiac index. Chest 1986; 89: 331-334.

100. Tolle F, Judy W, Yu P-L, Markand O. Reduced stroke volume related to pleural pressure in obstructive sleep apnea. J Appl Physiol: Respirat Environ Exercise Physiol 1983; 55: 1718-1724.

101. Shiomi T, Guilleminault C, Stoohs R, Schnittger I. Leftward shift of the interventricular septum and pulsus paradoxus in obstructive sleep apnea syndrome. Chest 1991; 100: 894-902.

102. Garpestad E, Katayama H, Parker J, et al. Stroke volume and cardiac output decrease at termination of obstructive apneas. J Appl Physiol 1992; 73: 1743-1748.

103. Garpestad E, Remsburg S, Parker J, Weiss J. Reinflation and arousal from sleep independently influence the decrease in left ventricular stroke volume at apnea termination. Am Rev Respir Dis 1993; 147: A1016.

104. Shepherd J. The lungs as receptor sites for cardiovascular regulation. Circulation 1981; 63: 1-10.

105. Brinker J, Weiss J, Lappé D, et al. Leftward septal displacement during right ventricular loading in man. Circulation 1980; 61: 626-633.

106. Brecher G. Mechanism of venous flow under different degrees of aspiration. Am J Physiol 1952; 169: 423-433.

107. Guyton A, Adkins L. Quantitative aspects of the collapse factor in relation to venous return. Am J Physiol 1954; 177: 523-527.

108. Natori H, Tamaki S, Kira S. Ultrasonographic evaluation of ventilatory effect on inferior vena caval configuration. Am Rev Respir Dis 1979; 120: 421-427.

109. Willeput R, Rondeaux C, Troyer AD. Breathing affects venous return from legs in humans. J Appl Physiol: Respirat Environ Exercise Physiol 1984; 57: 971-976.

110. Bonsignore MR, Marrone O, Romano S. Beat-by-beat analysis of pulmonary arterial pressure and flow during obstructive sleep apneas. Am Rev Respir Dis 1992; 145: A721.

111. Robotham J, Lixfeld W, Holland L, MacGregor D, Bryan A, Rabson J. Effects of respiration on cardiac performance. J Appl Physiol: Respirat Environ Exercise Physiol 1978; 44: 703-709.

112. Walley K, Ford L, Wood L. Effects of hypoxia and hypercapnia on the force-velocity relation of rabbit myocardium. Circ Res 1991; 69: 1616-1625.

113. Coleridge J, Coleridge H. Chemoreflex regulaton of the heart. In: Shepherd J, Abboud F, eds. Handbook of Physiology. Cardiovascular System. Section 2, Volume 1. Bethesda, MD, American Physiological Society, 1979; pp. 653-676.

114. Cross C, Rieben P, Barron C, Salisbury P. Effects of arterial hypoxia on the heart and circulation: an integrative study. Am J Physiol 1963; 205: 963-970.

115. Krasney J, Koehler R. Influence of arterial hypoxia on cardiac and coronary dynamics in the conscious sinoaortic-denervated dog. J Appl Physiol: Respirat Environ Exercise Physiol 1977; 43: 1012-1018.

116. Sullivan C, Berthon-Jones M, Issa F. Remission of severe obesity-hypoventilation syndrome after short-term treatment during sleep with nasal continuous positive airway pressure. Am Rev Respir Dis 1983; 128: 177-181.

117. Krieger J, Grucker D, Sforza E, Chambron J, Kurtz D. Left ventricular ejection fraction in obstructive sleep apnea. Effects of long-term treatment with nCPAP. Chest 1991; 100: 917-921.

118. Hanly P, Sasson Z, Zuberi N, Alderson M. Ventricular function in snorers and patients with obstructive sleep apnea. Chest 1992; 102: 100-105.

119. Lonsdorfer J, Meunier-Carus J, Lampert-Benignus E, et al. Aspects hémodinamiques et respiratoires du syndrome picwickien. Bull Eur Physiopathol Respir 1972; 8: 1181-1192.

120. Marrone O, Bellia V, Ferrara G, et al. Transmural pressure measurements. Importance in the assessment of pulmonary hypertension in obstructive sleep apneas. Chest 1989; 95: 338-342.

121. Marrone O, Bellia V, Pieri D, Salvaggio A, Bonsignore G. Acute effects of oxygen administration on transmural pulmonary artery pressure in obstructive sleep apnea. Chest 1992; 101: 1023-1027.

122. Emery C, Sloan P, Mohammed F, Barer G. The action of hypercapnia during hypoxia on pulmonary vessels. Bull Eur Physiopathol Respir 1977; 13: 763-776.

123. Marrone O, Bonsignore MR, Romano S. Pulmonary artery pressure in obstructive apneas: influence of intrathoracic pressure and hypoxia. Am Rev Respir Dis 1993; 147: A1017.

124. Buda A, Schroeder J, Guilleminault C. Abnormalities of pulmonary artery wedge pressure in sleep-induced apnea. Int J Cardiol 1981; 1: 67-74.

125. Chaudary B, Ferguson D, Speir W. Pulmonary edema as a presenting feature of sleep apnea syndrome. Chest 1982; 82: 122-124.

126. Schroeder J, Motta J, Guilleminault C. Hemodynamic studies in sleep apnea. In: Guilleminault C, Dement W, eds. Sleep Apnea Syndromes. New York, Alan R. Liss, 1978; pp. 177-196.

127. Iwase N, Kikuchi Y, Hida W, et al. Effects of phentolamine and carotid body resection on pulmonary artery and systemic artery pressure during repetitive airway obstruction. Am Rev Respir Dis 1989; 139: A181.

128. Naeije R, Lejeune P, Leeman M, Melot C, Closset J. Pulmonary vascular responses to surgical chemodenervation and chemical sympathectomy in dogs. $J$ Appl Physiol 1989; 66: 42-50.

129. Hoffstein V, Mateika J. Evening-to-morning blood pressure variations in snoring patients with and without obstructive sleep apnea. Chest 1991; 101: 379-384.

130. Parati G, Pomidossi G, Albini F, Malaspina D, Mancia G. Relationship of $24 \mathrm{~h}$ blood pressure mean and variability 
to severity of target-organ damage in hypertension. $J$ Hypertension 1987; 5: 93-98.

131. Verdecchia P, Schillaci G, Porcellati C. Dippers versus non-dippers. J Hypertension 1991; 9: S42-S44.

132. McGinty D, Beahm E, Stern N, Littner M, Sowers J, Reige W. Nocturnal hypotension in older men with sleeprelated breathing disorders. Chest 1988; 94: 305-311.

133. Podszus T, Kohler U, Mayer J, Penzel T, Peter J, von Wichert P. Systemic arterial pressure decreases during obstructive sleep apnea. Sleep Res 1986; 15: 155.

134. Peter J. Sleep apnea and cardiovascular diseases. In: Guilleminault C, Partinen M, eds. Obstructive Sleep Apnea Syndrome: Clinical Research and Treatment. New York, Raven Press Ltd, 1990; pp. 81-98.

135. Littner M, McGinty D. Blood pressure in sleep-related disordered breathing: a hypothesis. In: Peter J, Penzel T, Podszus T, von Wichert P, eds. Sleep and Health Risk. Berlin, Springer-Verlag, 1991; pp. 295-299.

136. Sullivan C, Grunstein R, Marrone O, Berthon-Jones M. Sleep apnea-pathophysiology: upper airway and control of breathing. In: Guilleminault $\mathrm{C}$, Partinen M, eds. Obstructive Sleep Apnea Syndrome. New York, Raven Press, 1990; pp. 49-69.

137. Lea S, Ali N, Goldman M, Loh L, Fleetham J, Stradling J. Systolic blood pressure swings reflect inspiratory effort during simulated obstructive apnea. In: Horne J, ed. Sleep 1990. Bochum, Pontenagel Press, 1990; pp. 178181.

138. Fitzgerald R, Robotham J, Anand A. Baroreceptor output during normal and obstructed breathing and Mueller maneuvers. Am J Physiol 1981; 240: H721-H729.

139. Somers V, Mark A, Zavala D, Abboud F. Influence of ventilation and hypocapnia on sympathetic nerve responses to hypoxia. J Appl Physiol 1989; 67: 2095-2100.

140. Somers V, Mark A, Abboud F. Interaction of baroreceptor and chemoreceptor reflex control of sympathetic nerve activity in normal humans. J Clin Invest 1991; 87: 1953-1957.

141. Hong S, Lin C, Lally D, et al. Alveolar gas exchanges and cardiovascular functions during breathholding with air. J Appl Physiol 1971; 30: 540-547.

142. Lin Y, Shida K, Hong S. Effects of hypercapnia, hypoxia, and rebreathing on circulatory response to apnea. $J$ Appl Physiol: Respirat Environ Exercise Physiol 1983; 54: 172-177.

143. Stoohs R, Guilleminault C. Cardiovascular responses to experimental sleep fragmentation in sleep apnea and normal subjects. Am Rev Respir Dis 1993; 147: A1014.

144. Aardweg J, Karemaker J. Repetitive apneas induce periodic hypertension in normal subjects through hypoxia. $J$ Appl Physiol 1992; 72: 821-827.

145. Cirignotta F, Mondini S, Schiavina M, Zucconi M, Coccagna G, Lugaresi E. Cheyne-Stokes breathing and systemic arterial pressure periodic pattern during sleep in central alveolar hypoventilation. Bull Eur Physiopathol Respir 1987; 23: 409-412.

146. Ringler J, Basner R, Shannon R, et al. Hypoxemia alone does not explain blood pressure elevations after obstructive apneas. J Appl Physiol 1990; 69: 2143-2148.

147. Ali N, Davies R, Fleetham J, Stradling J. The acute effects of continuous positive airway pressure and oxygen administration on blood pressure during obstructive sleep apnea. Chest 1992; 101: 1526-1532.

148. Pickering G, Sleight P, Smyth H. The relation of arterial pressure to sleep and arousal in man. J Physiol (Lond) 1967; 191: P76-P78.

149. Ali N, Davies R, Fleetham J, Stradling J. Periodic move- ments of legs during sleep associated with rises in systemic blood pressure. Sleep 1991; 14: 163-165.

150. American Sleep Disorders Association. EEG arousals: scoring rules and examples. Sleep 1992; 15: 174-184.

151. Rose CJ, Althaus J, Kaiser D, Miller E, Carey R. Acute hypoxemia and hypercapnia: increase in plasma catecholamines in conscious dogs. Am J Physiol 1983; 245: H924-H929.

152. Davidson D, Stalcup S, Mellins R. Systemic hemodynamics affecting cardiac output during hypocapnic and hypercapnic hypoxia. J Appl Physiol 1986; 60: 12301236.

153. Somers V, Mark A, Zavala D, Abboud F. Contrasting effects of hypoxia and hypercapnia on ventilation and sympathetic activity in humans. J Appl Physiol 1989; 67: 2101-2106.

154. Trzebski A. Arterial chemoreceptor reflex and hypertension. Hypertension 1992; 19: 562-566.

155. Neves F, Marson O, Baumgratz R, et al. Rapid eye movement sleep deprivation and hypertension. Hypertension 1992; 19: Suppl. II-202-206.

156. Vitiello M, Ralph D, Veuth R, Frommlet M, Prinz P. Sleep apnea, REM sleep and nighttime hypoxemia are associated with elevated plasma norepinephrine levels. Gerontologist 1985; 25: 119.

157. Fletcher E, Miller J, Schaaf W, Fletcher J. Urinary catecholamines before and after tracheostomy in patients with obstructive sleep apnea and hypertension. Sleep 1987; 10: 35-44.

158. Ehlenz K, Kohler U, Mayer J, Peter J, von Wichert P, Kaffarnich H. Plasma levels of catecholamines and cardiovascular parameters during sleep in patients with sleep apnea syndrome. In: Peter J, Podszus T, von Wichert P, eds. Sleep-related Disorders and Internal Diseases. Berlin, Springer-Verlag, 1987; pp. 321-325.

159. Krieger J, Schmidt M, Sforza E, et al. Urinary excretion of guanosine $3^{\prime}: 5^{\prime}$-cyclic monophosphate during sleep in obstructive sleep apnoea patients with and without nasal continuous positive airway pressure treatment. Clin Sci 1989; 76: 31-37.

160. Jennum P, Wildschiødtz P, Christensen N, Schwartz T. Blood pressure, catecholamines, and pancreatic polypeptide in obstructive sleep apnea with and without nasal continuous positive airway pressure (nCPAP) treatment. Am J Hypertens 1989; 2: 847-852.

161. Eisenberg E, Zimlichman E, Lavie P. Plasma norepinephrine levels in patients with sleep apnea syndrome. N Engl J Med 1990; 322: 932-933.

162. Baruzzi A, Riva R, Cirignotta F, Zucconi M, Lugaresi E. Atrial natriuretic peptide and catecholamines in obstructive sleep apnea syndrome. Sleep 1991; 14: 83-86.

163. Clark R, Boudoulas H, Schaal S, Schmidt H. Adrenergic hyperactivity and cardiac abnormality in primary disorders of sleep. Neurology 1980; 30: 113-119.

164. Marrone O, Riccobono L, Salvaggio A, Mirabella A, Bonanno A, Bonsignore MR. Catecholamine and blood pressure in obstructive sleep apnea syndrome. Chest 1993; 103: 722-727.

165. Krieger J, Imbs J, Schdmidt M, Kurtz D. Renal function in patients with obstructive sleep apnea. Effects of nasal continuous positive airway pressure. Arch Intern Med 1988; 148: 1337-1340.

166. Krieger J, Sforza E, Barthelmebs M, Imbs J, Kurtz D. Overnight decrease in hematocrit after nasal CPAP treatment in patients with OSA. Chest 1990; 97: 729-730.

167. Krieger J, Sforza E, Delanoe C, Petiau C. Decrease in haematocrit with continuous positive airway pressure 
treatment in obstructive sleep apnoea patients. Eur Respir $J$ 1992; 5: 228-233.

168. Marrone O, Spatafora M, Mirabella A, et al. Urinary protein excretion in patients with obstructive sleep apnea syndrome. In: Horne J, ed. Sleep 1990. Bochum, Pontenagel Press, 1990; pp. 188-190.

169. Ehlenz K, Peter J, Schneider H, et al. Renin secretion is substantially influenced by obstructive sleep apnea syndrome. In: Horne J, ed. Sleep 1990. Bochum, Pontenagel Press, 1990; pp. 193-195.

170. Krieger J, Follenius M, Sforza E, Brandenberger G. Water and electrolyte metabolism in obstructive sleep apnea. In: Horne J, ed. Sleep 1990. Bochum, Pontenagel Press, 1990; pp. 429-434.

171. Follenius M, Krieger J, Krauth M, Sforza E, Brandenberger G. Obstructive sleep apnea treatment: peripheral and central effects on plasma renin activity and aldosterone. Sleep 1991; 14: 211-217.

172. Krieger J, Follenius M, Sforza E, Brandenberger G, Peter J. Effects of treatment with nasal continuous positive airway pressure on atrial natriuretic peptide and arginin vasopressin release during sleep in patients with obstructive sleep apnoea. Clin Sci 1991; 80: 443-449.

173. Krieger J, Benzoni D, Sforza E, Sassard J. Urinary excretion of prostanoids during sleep in obstructive sleep apnoea patients. Clin Exp Pharmacol Physiol 1991; 18: 551-555.

174. Neri-Serneri G, Castellani S, Scarti L, et al. Repeated sympathetic stimuli elicit the decline and disappearance of prostaglandin modulation and an increase of vascular resistance in humans. Circ Res 1990; 67: 580-588.

175. Bradley T, Rutherford R, Grossman R, et al. Role of daytime hypoxemia in the pathogenesis of right heart failure in the obstructive sleep apnea syndrome. Am Rev Respir Dis 1985; 131: 835-839.

176. Fletcher E, Schaaf J, Miller J, Fletcher J. Long-term cardiopulmonary sequelae in patients with sleep apnea and chronic lung disease. Am Rev Respir Dis 1987; 135: 525-533.

177. Weitzenblum E, Krieger J, Apprill M, et al. Daytime pulmonary hypertension in patients with obstructive sleep apnea syndrome. Am Rev Respir Dis 1988; 138: 345359.

178. Flenley D. Sleep in chronic obstructive lung disease. Clin Chest Med 1985; 6: 651-661.

179. Krieger J, Sforza E, Apprill M, Lampert E, Weitzenblum E, Ratomaharo J. Pulmonary hypertension, hypoxemia, and hypercapnia in obstructive sleep apnea patients. Chest 1989; 96: 729-737.

180. Sforza E, Krieger J, Weitzenblum E, Apprill M, Lampert E, Ratamaharo J. Long-term effects of treatment with nasal continuous positive pressure on daytime lung function and pulmonary hemodynamics in patients with obstructive sleep apnea. Am Rev Respir Dis 1990; 141: 866-870.

181. Laks L, Lehrhaft B, Berthon-Jones M, Sullivan C. Obstructive sleep apnea: effects of long-term treatment with nCPAP on pulmonary vascular responsiveness to acute hypoxia. Am Rev Respir Dis 1993; 147: A535.

182. Berman E, DiBenedetto R, Causey D, et al. Right ventricular hypertrophy detected by echocardiography in patients with newly diagnosed obstructive sleep apnea. Chest 1991; 100: 347-350.

183. Davidson WJ, Stauffer J, Reeves-Hoché M, Zwillich C. Cardiac sequelae of sleep-disordered breathing or obstructive sleep apnea: new evidence for right ventricular dysfunction. Am Rev Respir Dis 1993; 147: A1015.

184. DiBenedetto R, Goodman L, Rollings R, Berman E,
Causey D. Whither goest the right ventricle in obstructive sleep apnea? Chest 1992; 102: 5-6.

185. Escourrou P, Jirani A, Nedelcoux H, Duroux P, Gaultier C. Systemic hypertension in sleep apnea syndrome. Chest 1990; 98: 1362-1365.

186. Marrone O, Insalaco G, Salvaggio A, Costanza B, Greco $\mathrm{V}$, Bonsignore MR. Daytime systemic hypertension in severe obstructive sleep apnea syndrome. J Sleep Res 1992; 1: 143.

187. Rauscher H, Popp W, Zwick H. Systemic hypertension in snorers with and without sleep apnea. Chest 1992; 102: 367-371.

188. Guilleminault C, Simmons F, Motta J, et al. Obstructive sleep apnea syndrome and tracheostomy. Long-term follow-up experience. Arch Intern Med 1981; 141: 985-988.

189. Ross R, Daniels S, Loggie J, Meyer R, Ballard E. Sleep apnea-associated hypertension and reversible left ventricular hypertrophy. J Pediatr 1987; 111: 253-255.

190. Perlund J, White W. Central hemodynamics and 24 hour blood pressure in obstructive sleep apnea syndrome: effects of corrective surgery. Am J Med 1990; 88: 678-682.

191. Mayer J, Becker H, Brandenburg U, Penzel T, Peter JH, von Wichert P. Blood pressure and sleep apnea: results of long-term nasal continuous positive airway pressure therapy. Cardiology 1991; 79: 84-92.

192. Sforza E, Capecchi V, Lugaresi E. Hemodynamic effects of short-term nasal continuous positive airway pressure therapy in sleep apnoea syndrome: monitoring by a finger arterial pressure device. Eur Respir J 1992; 5: 858-863.

193. Norton P, Dunn EV. Snoring as a risk factor for disease: an epidemiological survey. $\mathrm{Br}$ Med $J$ 1985; 291: 630-633.

194. Telakivi T, Partinen M, Koskenvuo M, Salmi T, Kaprio J. Periodic breathing and hypoxia in snorers and controls: validation of snoring history and association with blood pressure and obesity. Acta Neurol Scand 1987; 76 : 69-75.

195. Gislason T, Åberg H, Taube A. Snoring and systemic hypertension. Acta Med Scand 1987; 222: 415-421.

196. Hoffstein V, Rubinstein I, Mateika S, Slutsky A. Determinants of blood pressure in snorers. Lancet 1988; ii: $992-994$.

197. Schmidt-Nowara W, Coultas D, Wiggins C, Skipper B, Samet J. Snoring in a Hispanic-American population. Arch Intern Med 1990; 150: 597-601.

198. Mateika J, Mateika S, Slutsky A, Hoffstein V. The effect of snoring on mean arterial blood pressure during nonREM sleep. Am Rev Respir Dis 1992; 145: 141-146.

199. Jennum P, Hein H, Suadicani P, Gyntelberg F. Cardiovascular risk factors in snorers. A cross-sectional study of 3,323 men aged 54 to 74 years: the Copenhagen male study. Chest 1993; 102: 1371-1376.

200. Bloom J, Kaltenborn W, Quan S. Risk factors in a general population for snoring. Importance of cigarette smoking and obesity. Chest 1988; 93: 678-683.

201. Rauscher H, Formanek D, Popp W, Zwick H. Nasal CPAP and weight loss in hypertensive patients with obstructive sleep apnoea. Thorax 1993; 48: 529-533.

202. Lavie P, Yoffe N, Berger I, Peled R. The relationship between the severity of sleep apnea syndrome and $24 \mathrm{~h}$ blood pressure values in patients with obstructive sleep apnea. Chest 1993; 103: 717-721.

203. Kales A, Bixler E, Cadieux R, et al. Sleep apnoea in a hypertensive population. Lancet 1984; ii: 1005-1008.

204. Warley A, Mitchell J, Stradling J. Prevalence of nocturnal hypoxaemia amongst men with mild to moderate hypertension. Q J Med 1988; 256: 637-644. 
205. Hirshkowitz M, Karacan I, Gurakar A, Williams R. Hypertension, erectile dysfunction, and occult sleep apnea. Sleep 1989; 12: 223-232.

206. Isaksson H, Svanborg E. Obstructive sleep apnea syndrome in male hypertensives, refractory to drug therapy. Nocturnal automatic blood pressure measurements - an aid to diagnosis? Clin Exp Hyper Theory and Practice 1991; A13: 1195-1212.

207. Gleadhill IC, McCrum EE, Patterson CC, Johnston GD, Evans A, MacMahon J. Sleep-related hypoxaemia in hypertensive and normotensive men. Thorax 1993; 48: 534-536.

208. Przybylski J, Sabbah H, Stein P. Why do patients with essential hypertension experience sleep apnea syndrome? Med Hypotheses 1986; 20: 173-177.

209. Heath D. The human carotid body. Thorax 1983; 38: 561-564.

210. Donnelly D, Haddad G. Carotid chemotransduction: mechanisms and development. In: Gaultier C, Escourrou P, Curzi-Dascalova L, eds. Sleep and Cardiorespiratory Control. Montrouge, France, Colloque INSERM/John Libbey Eurotext Ltd, 1991; pp. 35-43.

211. Shiner R, Carroll N, Sawicka E, Simonds A, Branthwaite M. Role of nocturnal hypoxemia in the genesis of systemic hypertension. Cardiology 1990; 77: 25-29.

212. Hedner J, Wilcox I, Laks L, Grunstein R, Sullivan C. A specific and potent pressor effect of hypoxia in patients with sleep apnea. Am Rev Respir Dis 1992; 146: 1240-1245.

213. Tafil-Klawe $\mathrm{M}$, Raschke $\mathrm{F}$, Becker $\mathrm{H}$, et al. Investigations of arterial baro- and chemoreflexes in patients with arterial hypertension and obstructive sleep apnea syndrome. In: Peter J, Penzel T, Podszus T, von Wichert P, eds. Sleep and Health Risk. Berlin, Springer-Verlag, 1991; pp. 319-334.

214. Vlachogianni ED, Sandhagen B, Gislason T, Stålenheim
G. High ventilatory response to hypoxia in hypertensive patients with sleep apnea. Uppsala J Med Sci 1989; 94: 89-94.

215. Somers V, Mark A, Abboud F. Potentiation of sympathetic nerve responses to hypoxia in borderline hypertensive subjects. Hypertension 1988; 11: 608-612.

216. Trzebski A, Tafil M, Zoltowski M, Przybylski J. Increased sensitivity of the arterial chemoreceptor drive in young men with mild hypertension. Cardiovasc Res 1982; 16: 163-172.

217. Fletcher E, Lesske J, Behm R, Miller CC III, Stauss H, Unger T. Carotid chemoreceptors, systemic blood pressure, and chronic episodic hypoxia mimicking sleep apnea. J Appl Physiol 1992; 72: 1978-1984.

218. Fletcher E, Lesske J, Culman J, Miller C, Unger T. Sympathetic denervation blocks blood pressure elevation in episodic hypoxia. Hypertension 1992; 20: 612-619.

219. Kuwahira I, Heisler N, Piiper J, Gonzales NC. Effect of chronic hypoxia on hemodynamics, organ blood flow and $\mathrm{O}_{2}$ supply in rats. Respir Physiol 1993; 92: 227-238.

220. Genovese A, Chiariello M, Latte S, De Alfieri W, Condorelli M. Bilateral ventricular hypertrophy in rats exposed to acute or chronic hypobaric hypoxia. Respiration 1983; 44: 289-293.

221. Hedner J, Ejnell H, Caidhal K. Left ventricular hypertrophy independent of hypertension in patients with obstructive sleep apnoea. J Hypertension 1990; 8: 941946.

222. Lembo G, Napoli R, Capaldo B, et al. Abnormal sympathetic overactivity evoked by insulin in skeletal muscle of patients with essential hypertension. J Clin Invest 1992; 90: 24-29.

223. Mion DJ, Krieger E. Blood pressure regulation after deprivation of rapid eye movement sleep in rats. $J$ Hypertension 1988; 6: S74-S76. 